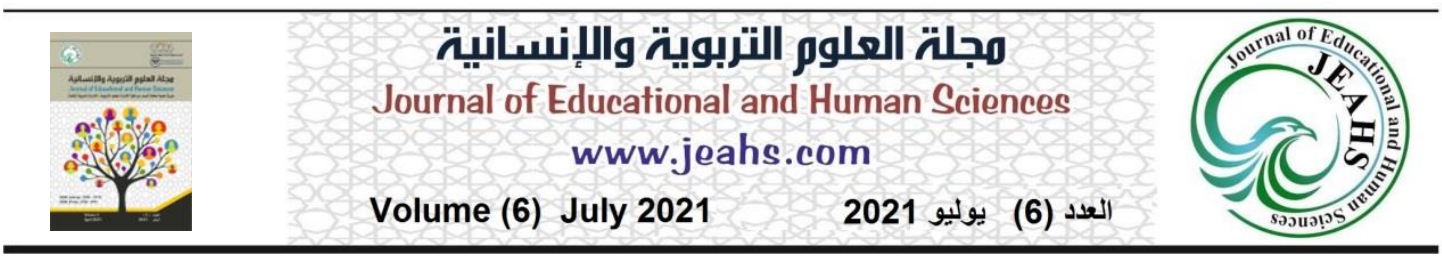

\title{
حرفة صياغة الذهب المعاصرة في مدينة الديوانية (مقاربة انثروبولوجية)
}

\author{
الم.د.د. عدنان مطر ناصر

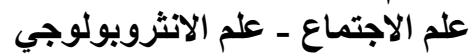

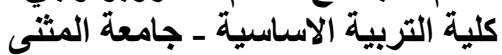

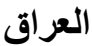

البريد الاككتروني: adnannaser900@mu.edu.iq

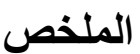

ان هدف البحث معرفة ما وصل إليه فن صياغة الذهب في المجتمع العر اقي بشكل عام والمجتمع المحلي (مدينة

الديو انية انموذجا) بشكل خاص من نطورات في طبيعة مواد واساليب وتقنيات التكنولوجية الحديثة في نطوير الصياغة باطار انثروبولوجي داخل السوق الكبير في المدينة القديمة التي تمثل قلب ومركز محافظة القادية من من وجهة نظر عينة من صاغة محلات الذهب و الصناع العاملين معهم و البالغ عددهم(20) صائغ و( 40) صانع ماهر وشبه ماهر اعتمادا على المنهج الانثروبولوجي بطريقة العينة العمدية كمجال للبحث، واستعمال الادوات المناسبة للمنهج الانثروبولوجي كالمقابلة والملاحظة والمخبرون لجمع المعلومات. وتوصل البحث الى مجموعة من

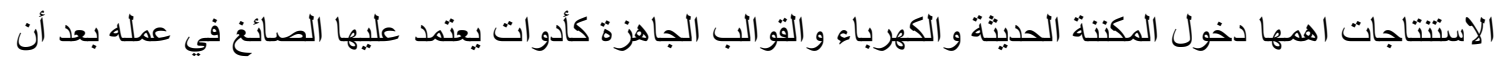
كان عمله يدوي. وقادت الى عدد من التوصيات منها ضرورة العمل لتطوير صناعة وصياغة الذهب في المدينة لإيجاد صناعات عر اقية ومحلية ذات اهمية استر اتيجية تنافس الصناعات الاجنبية.

الكلمات المفتاحية: حرفة، صياغة، ذهب، معاصرة، الانثروبولوجيا. 


\title{
Contemporary Goldsmithing Craft in Al- Diwaniyah City (An anthropological approach)
}

\author{
Assist. Prof. Dr. Adnan Mutter Nassir \\ Sociology - Anthropology \\ College of Basic Education- University of Al-Muthanna- Iraq \\ Email: adnannaser900@mu.edu.iq
}

\begin{abstract}
The aim of the research is to know what the art of goldsmithing has reached in the Iraqi local community (Al-Diwaniyah city as a model) of developments in the nature of materials, methods and techniques of modern technology in the development of goldsmithing with an anthropological framework within the big market in the old city, which represents the heart and center of Al-Qadisiyah Governorate from the point of view of a sample From the goldsmiths of the gold shops and the craftsmen working with them, who number (20) goldsmiths and (40) skilled and semi-skilled craftsmen, depending on the anthropological method in the method of the intentional sampling as a field of research, and using the appropriate tools for the anthropological method such as interview, observation and informants to collect information.

The research reached a set of conclusions, the most important of which is the entry of modern mechanization, electricity and ready-made molds as tools that the goldsmith relies on in his work after his work was manual. And it led to a number of recommendations, including the need to work to develop the gold industry and forge to create local Iraqi industries of strategic importance to compete with foreign industries.
\end{abstract}

Keywords: craft, goldsmithing, contemporary, anthropology. 


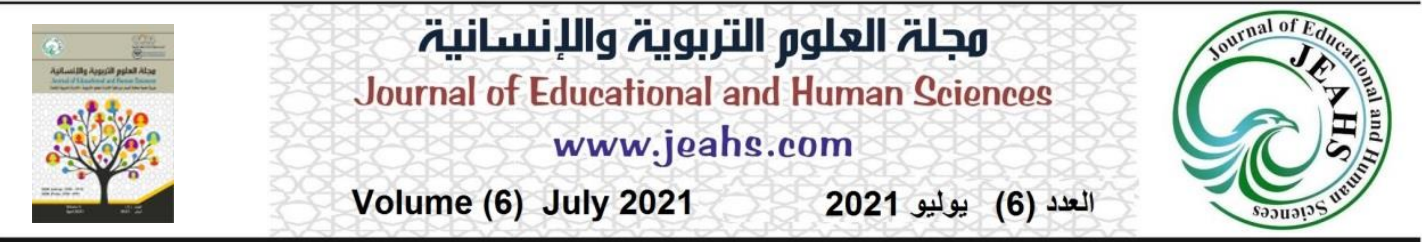

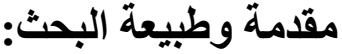

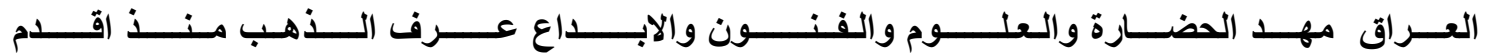

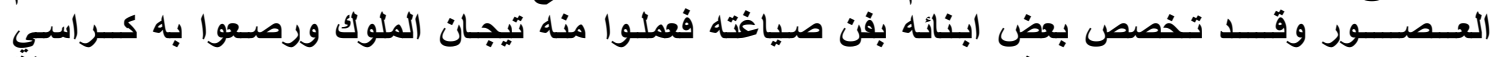

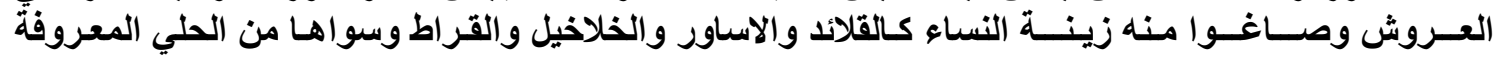

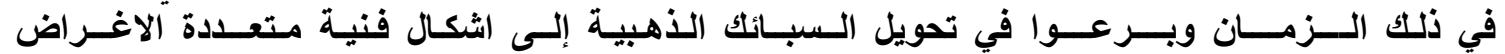

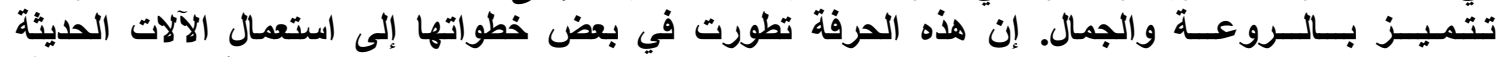

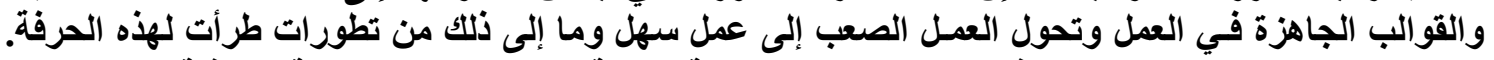

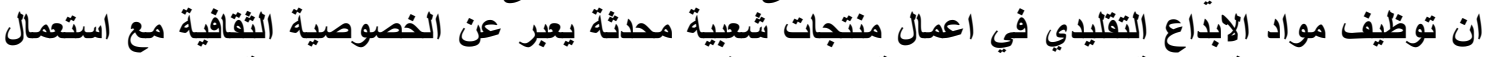

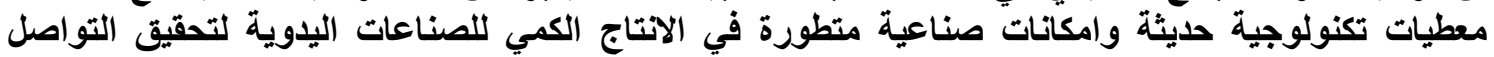

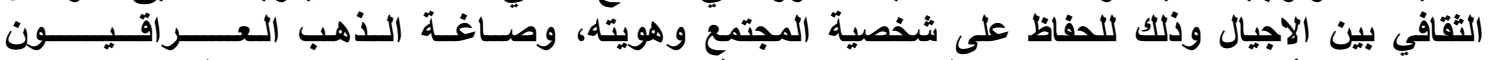

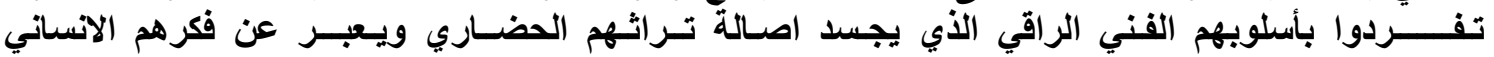

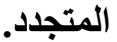

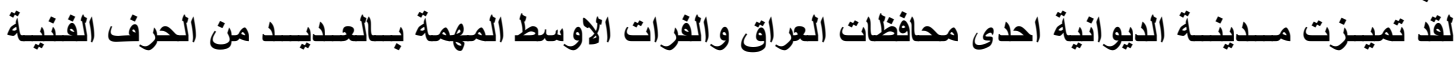

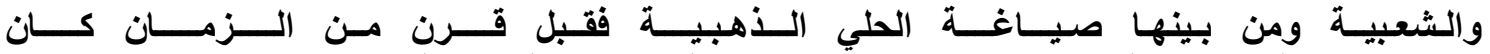

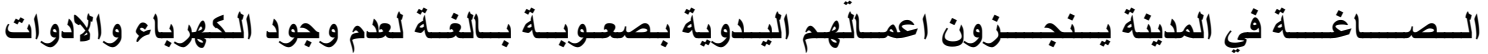

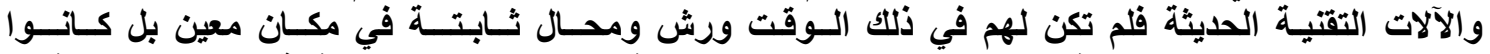

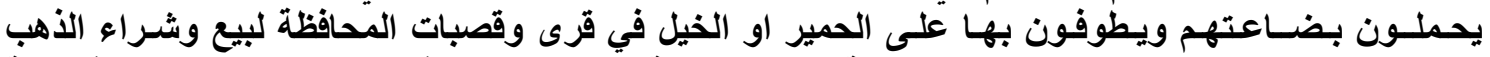

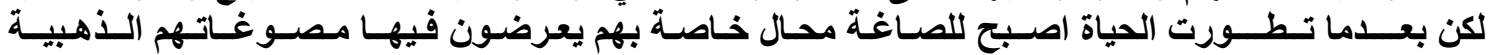

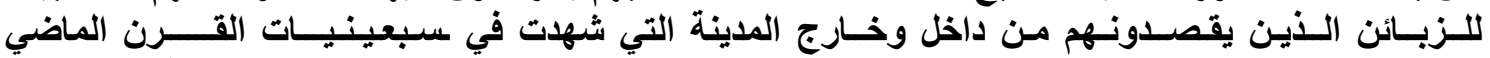

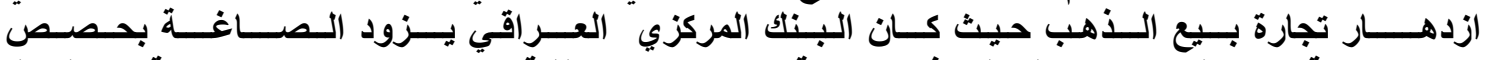

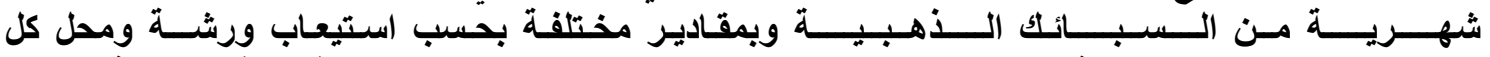

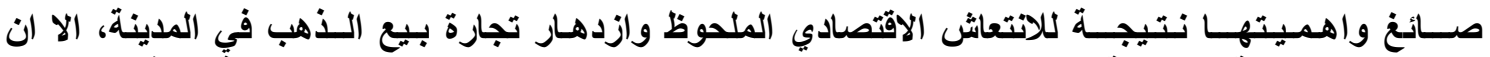

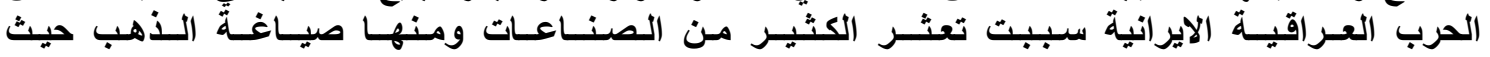

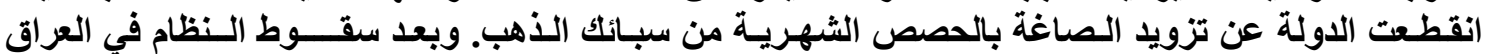

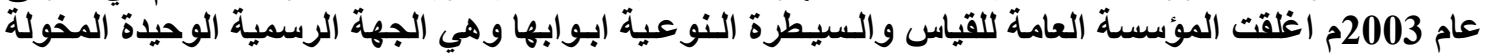

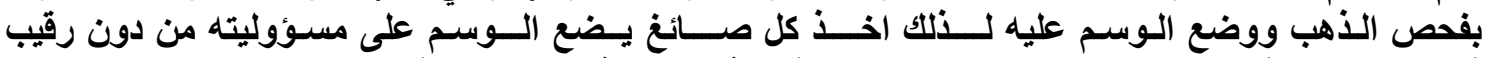

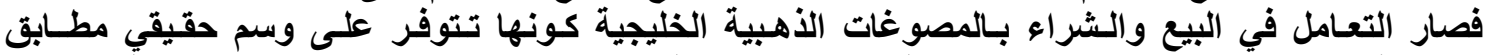

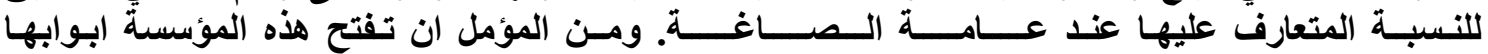

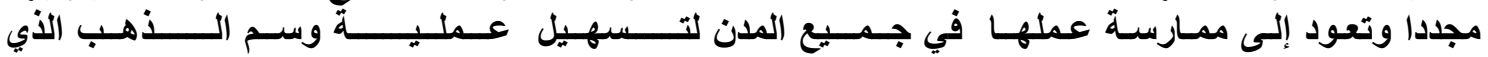

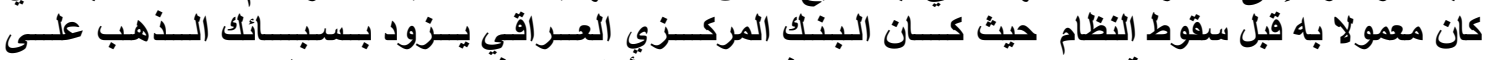

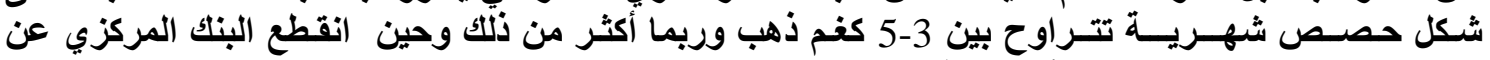

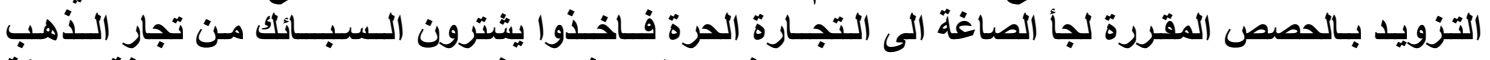

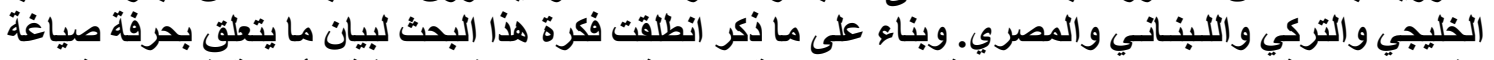

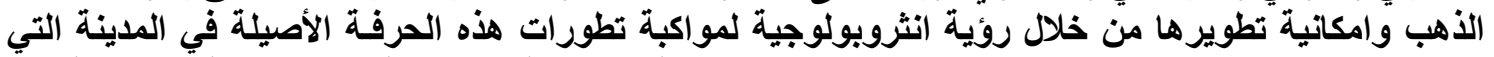

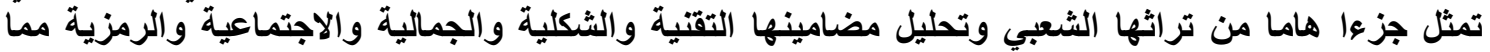
يساعد على تنميتها في اطار ثقافي مبدع وخصوصية ونتئ منميزة في ظل مجتمع متغير.

$$
\text { 1المبحث الاول: منهجية البحث ومفاهيمه: }
$$

أ- ما الجو انب المعاصرة لحرفة صياغة الذهب في مدينة الديو انية.

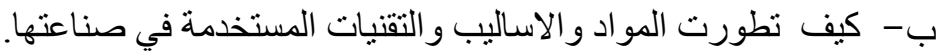




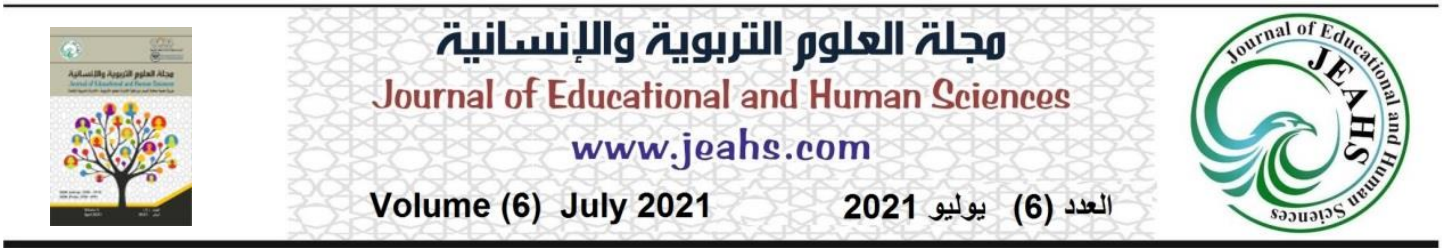

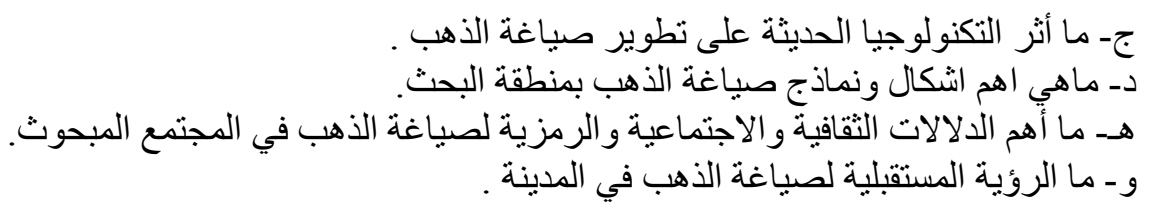

$$
\text { 2- هدف البحث: يمكن تلخيص اهداف البحث على النحو الآتي : }
$$

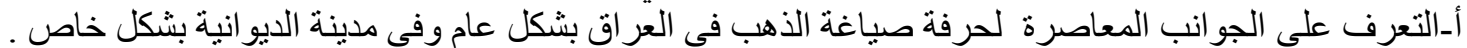

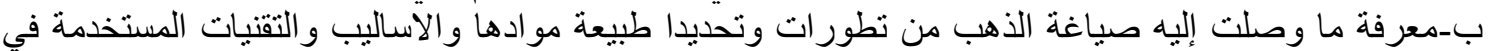

صناعنها. ج- معرفة اثر التكنولوجيا الحديثة على تطوير صياغة الذهب .

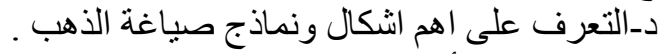

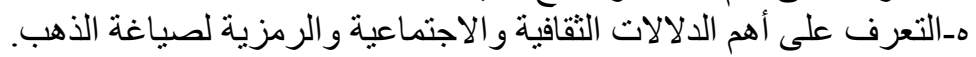

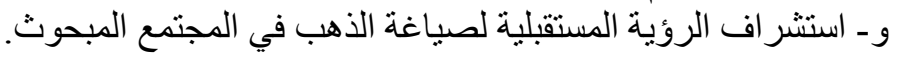

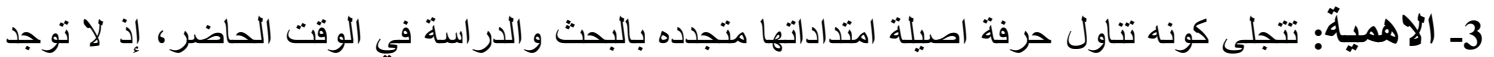

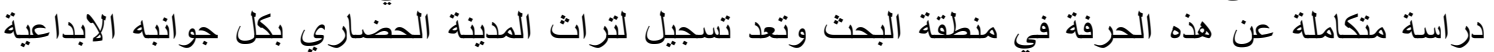

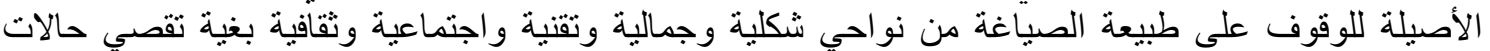
التواصل الحضاري عبر الاجيال المتعاقبة.

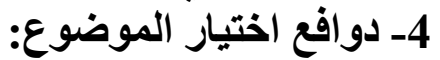
أـ عدم الأهمام بهذه الحرفة من قبل الباحثين حيث نجد معظمه ركزوا في بحوثهم الأكاديمية على صناعات أخرى

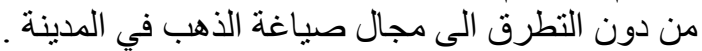

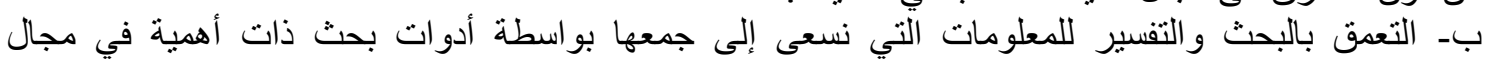
الانثروبولوجيا. ج- اعادة الاعنبار لهذا النوع من القطاعات التقليدية و التعريف بها لأنها تشكل إرثا ثقافيا واجتماعيا قيما واعطاء

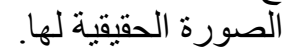
دـارتباط معظم البحوث و والدر اسات بموضو عات ذات ذات صلة بحرف تقليدية منقرضة او التي في طريقها الى الاندثار

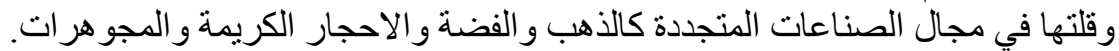

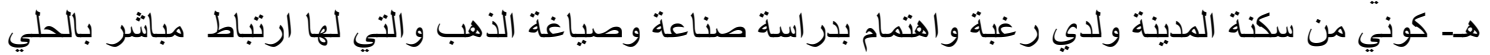

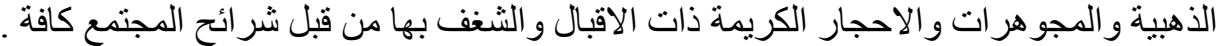
5-المنهج وادواته الاراسة :

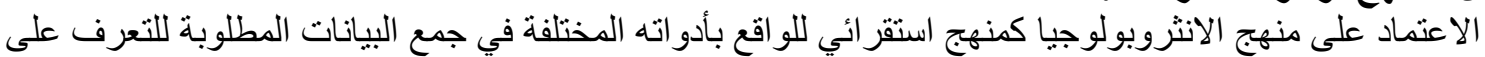

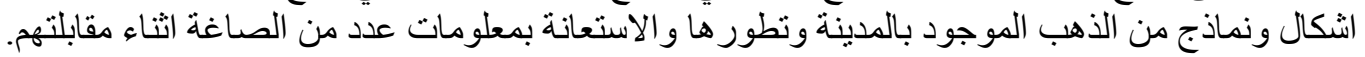

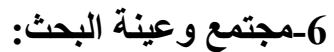

وبعد التطرق لمنهج البحث المعتمد في هذا البحث تم تحديد مجتمع الدراسة في مدينة الديو انية (السوق الكبير )

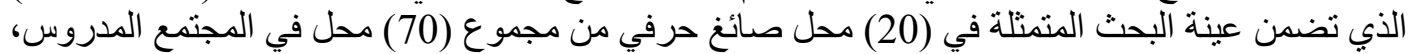

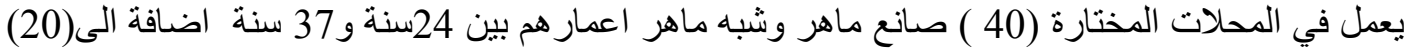

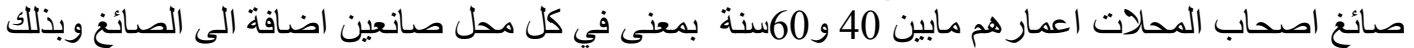

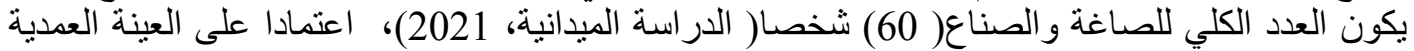

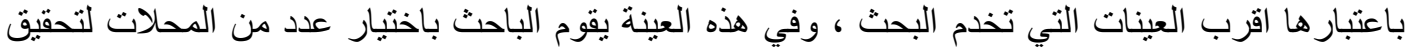

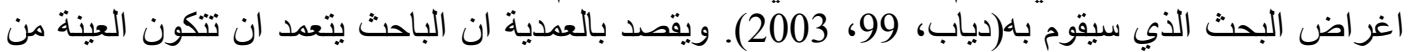

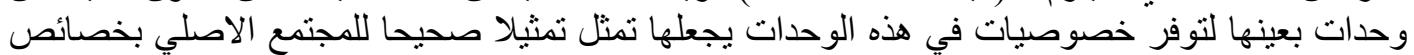
ومزايا تمثيلية للمجتمع (Lauretto. M, et al,2012,192). 


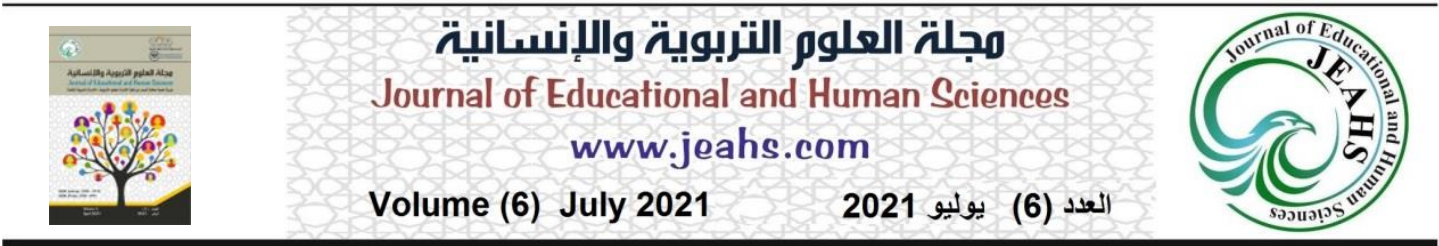

7- مجالات البحث:

أـالمجال المكاني: مدينة الديو انية ( السوق القديم) المنطقة القديمة التي تمثل مركز محافظة القادسية.

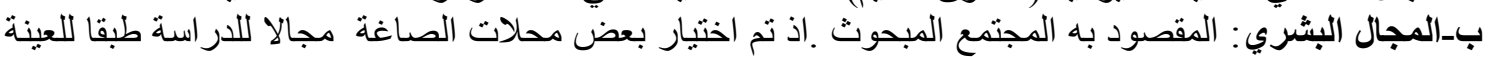

المنتخبة.

ج-المجال الزماني: غطى الجهد الميداني المرحلة الزمنية الممندة ما بين 2021/1/1 ولغاية 2021/3/1.

ثانيا_مفاهيم البحث:

1- الحرفة : صناعاتهات بيتيه أو ورش عمل ومحلات تستعمل فيها الآلات للمساعدة ( ناصر ، 2020، 17) تتميز منتجاتها بصفة فنية وتتطلب مهارة مهنية كصياغة الذهب (Kokko\& Dillon,2010,488). تلتبي التهاعي

حاجات المجتمع المادية و الثقافية و الاجتماعية ( عبد الرحمن، 2002، 57ة كنية

2-الصياغة: حرفة دقيقة لها صاغه متخصصون يصنعون الحلي الذهبيـة للنساء( حجول، اساور،اقر اط) ورجالية

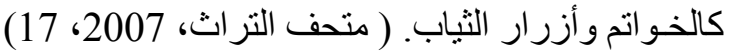

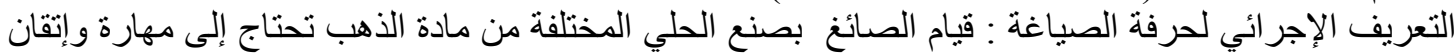

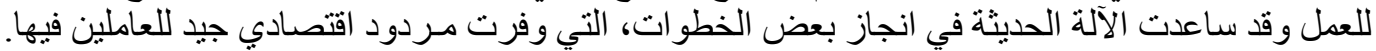

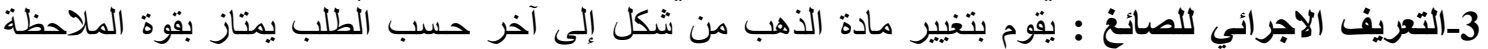

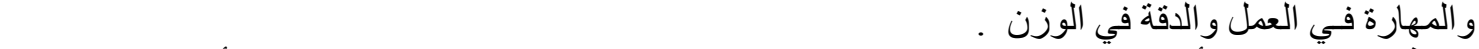

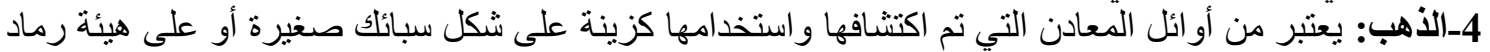

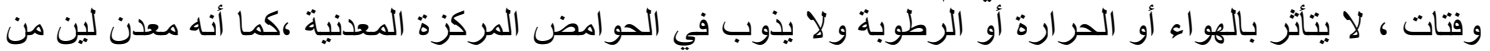

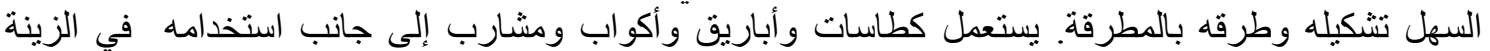

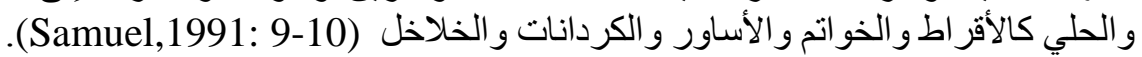

5- التعريف الاجرائي للمعاصرة: تعني مو اكبة العصر و التأثر بسماته وظروفه الزمانية و المكانية .

6-الانثروبولوجيا: يهتم بدراسة الانسان دراسة كلية شمولية من حيث قيمه ومكتسباته الثقافية مشتق من الكلمة

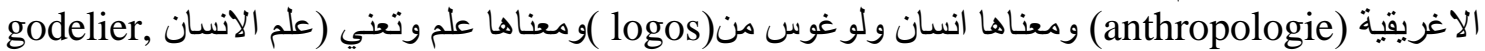

.(2015: 33-38)

المبحث الثاني :الاطار النظري.

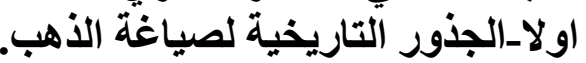

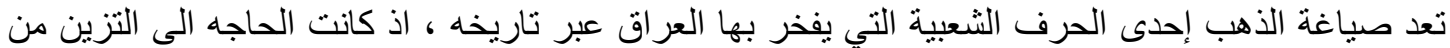

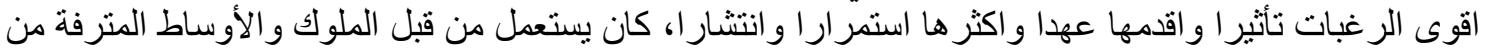

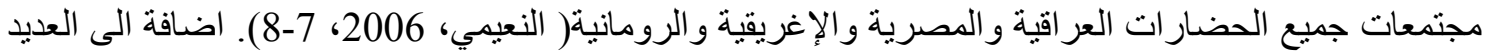

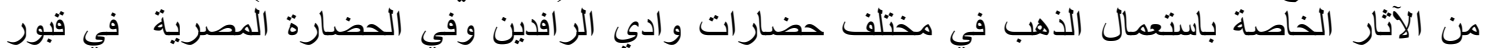

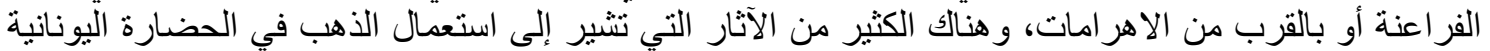

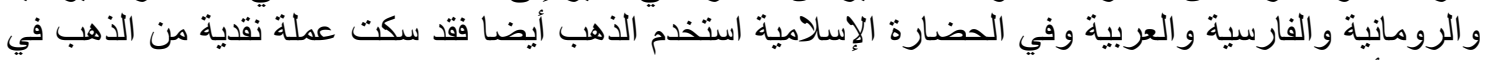

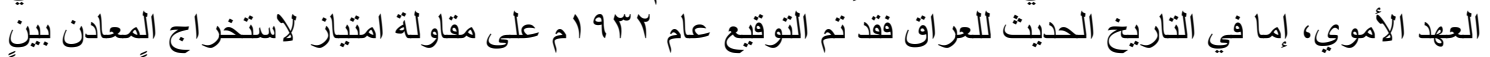

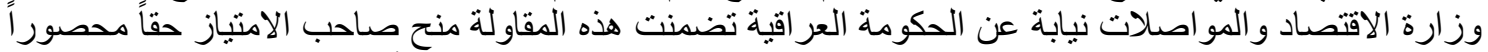

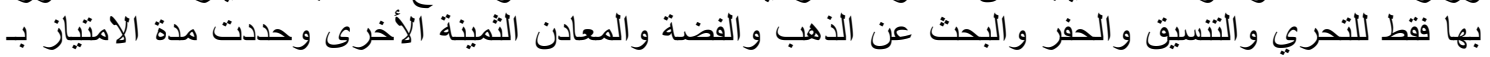

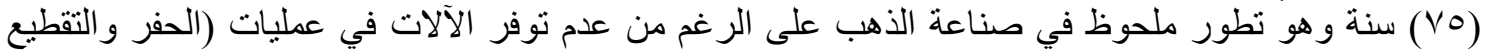

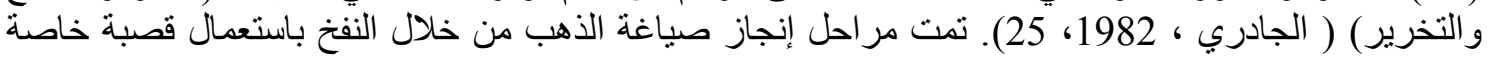
لرفع حرارة النار وتليين المعدن قبل تقطيعها، اذ يصاغ الذهب على شكل خيوط تشبه خيوط النسيج( كجة جي ، 


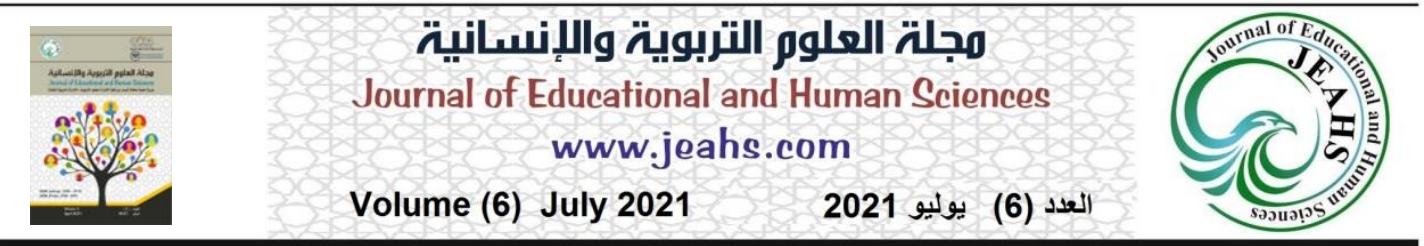

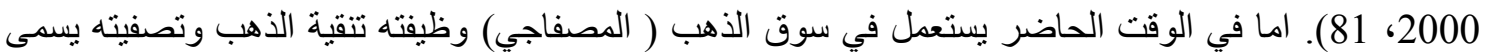

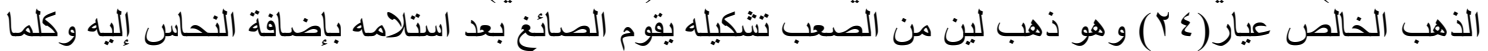

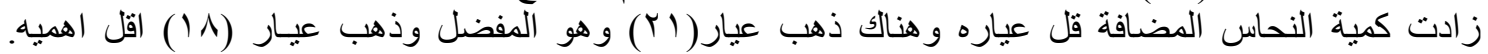

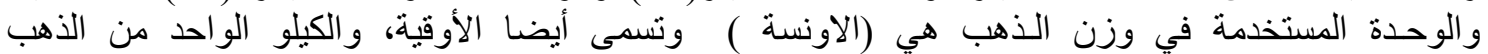

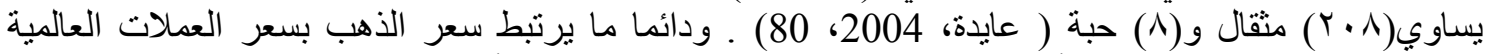

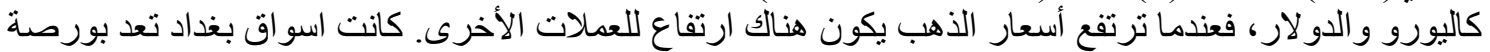

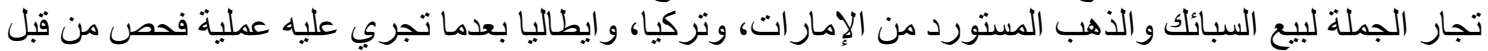

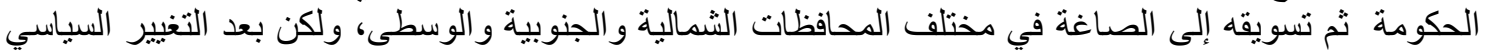

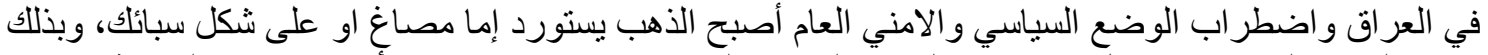

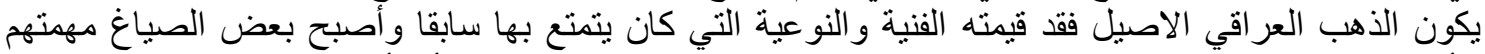

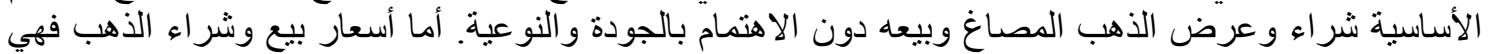

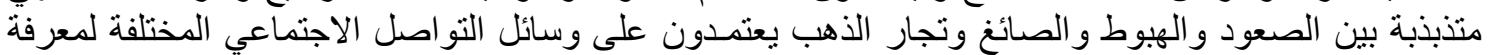

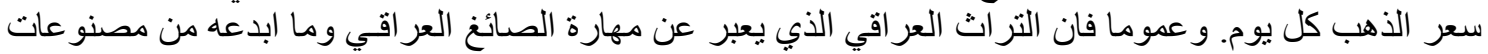

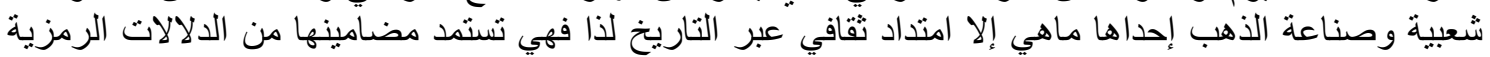

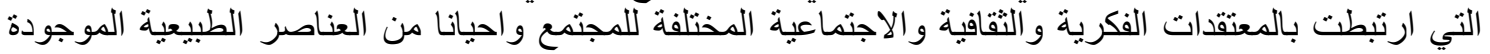

\section{ثانيا: النظريات المفسرة للبحث:}

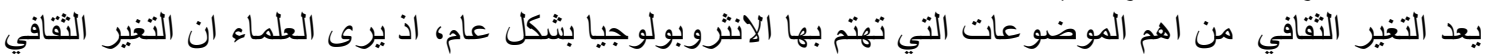

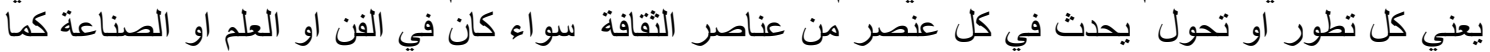

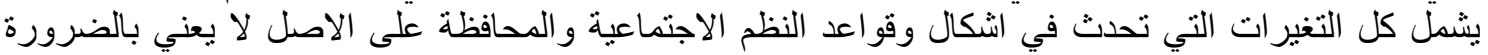

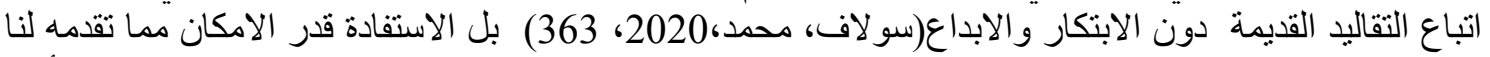

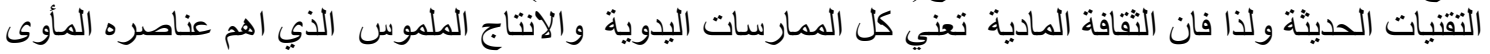

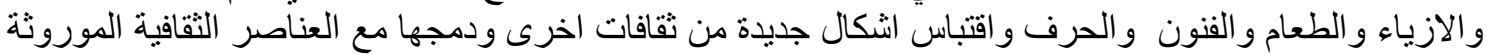

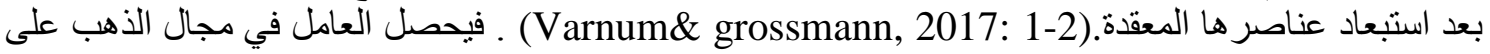

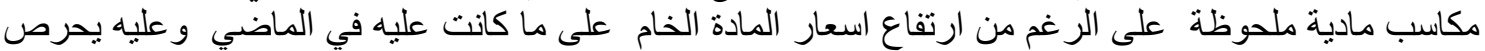

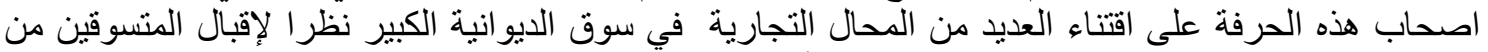

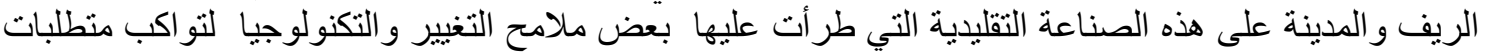

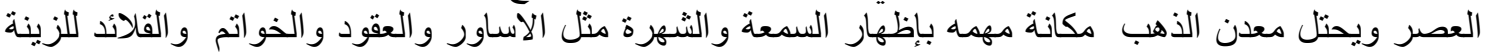

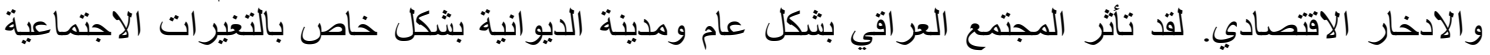

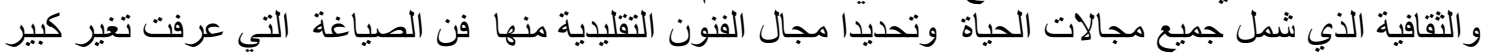

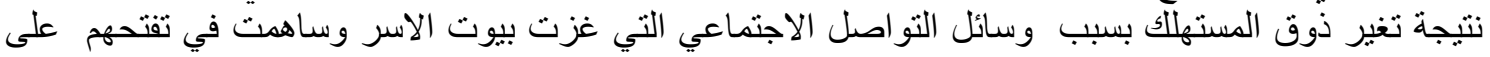

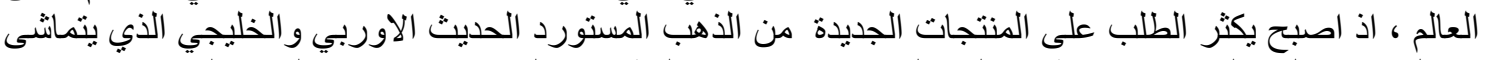

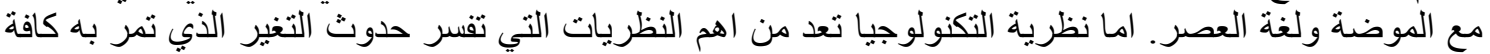

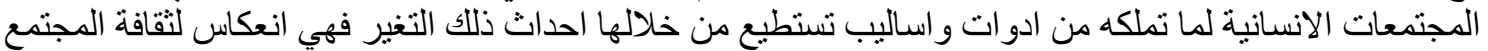

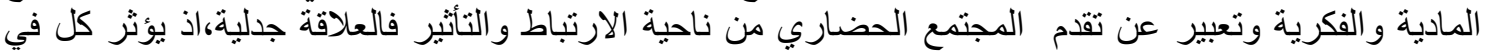

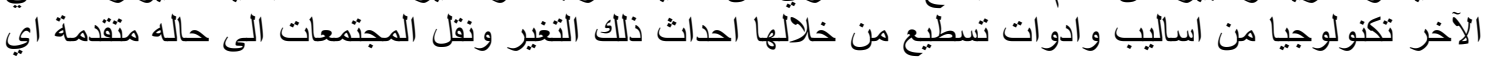

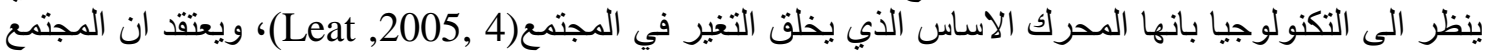

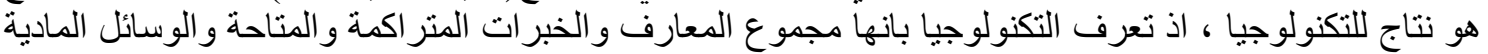

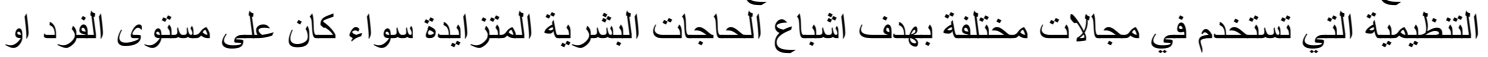

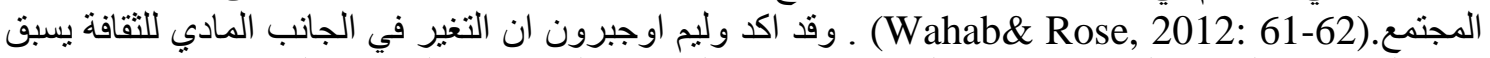

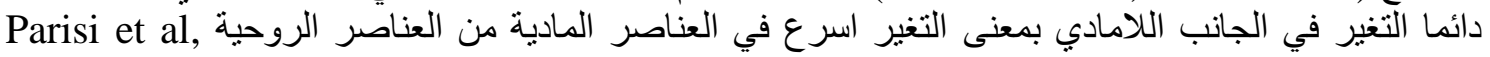

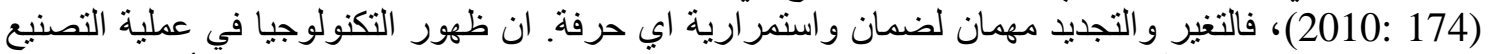
نظر الوجود المكائن و الآلات الحديثة طورت كثير ا من طبيعة الأشكال الفنية وحولتها الى صناعات ألية بعد ما كان 


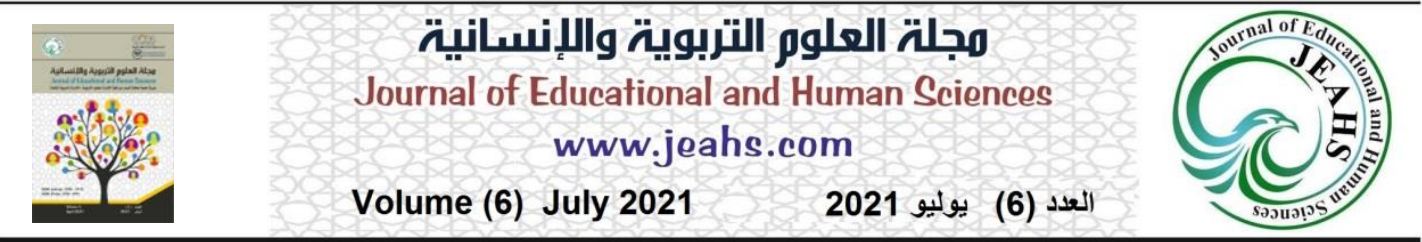

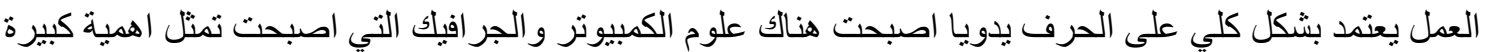

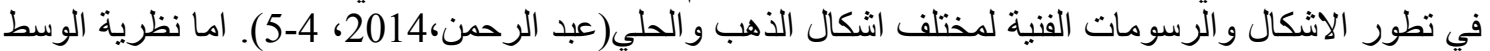

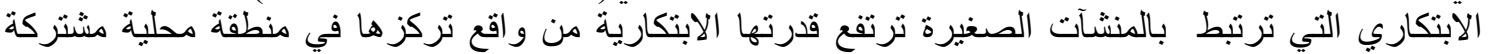

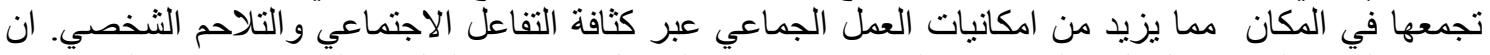

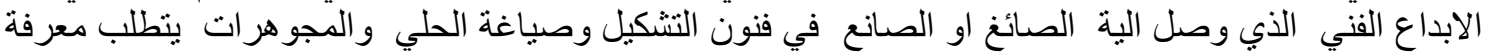

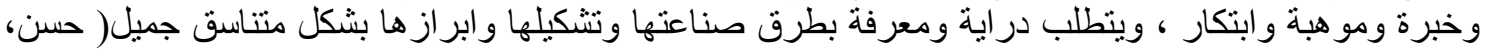

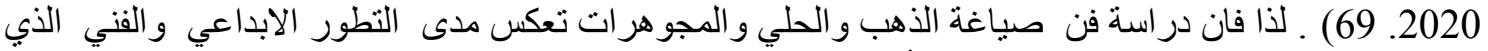

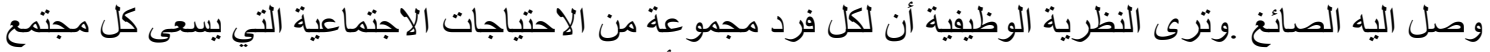

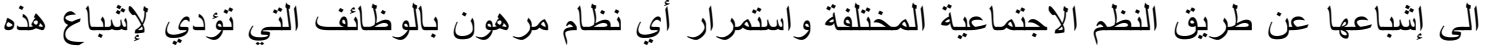

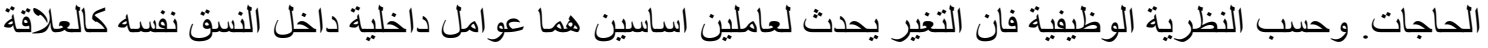

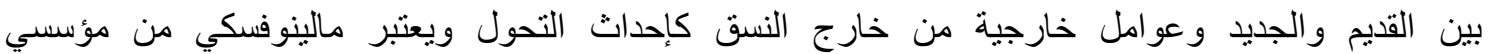

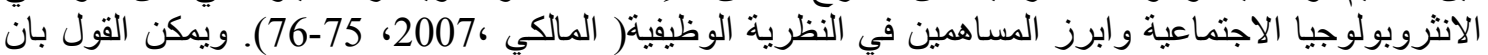

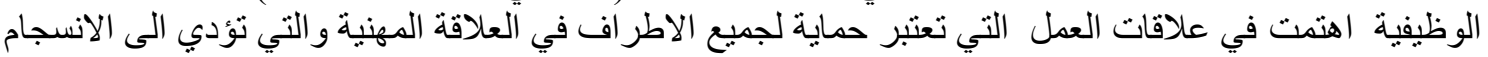

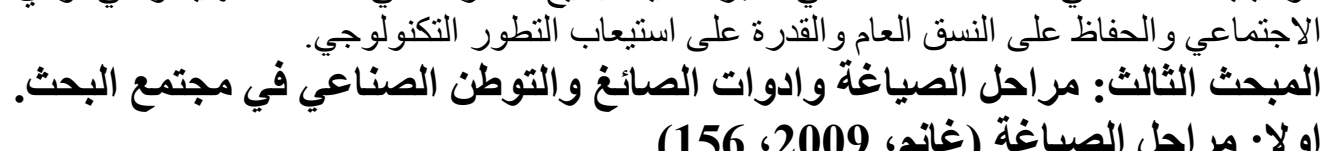

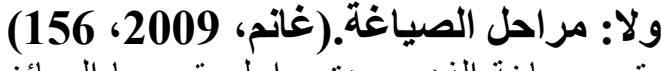

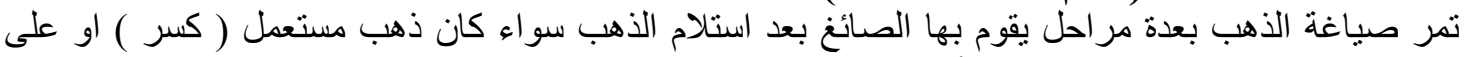

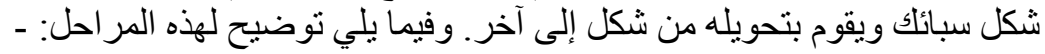

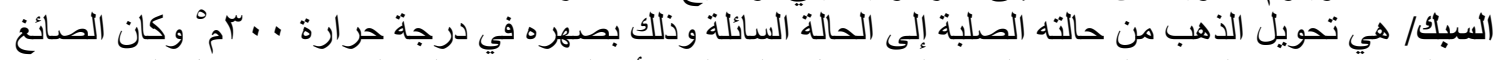

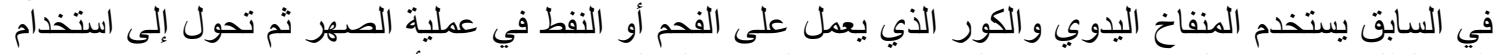

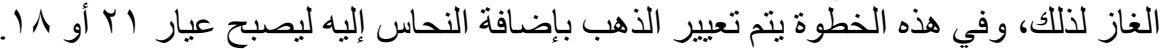

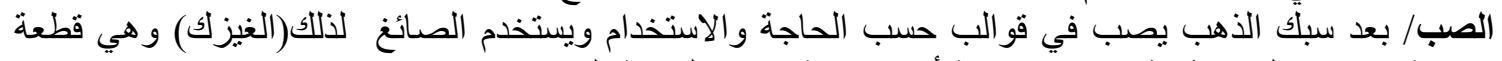

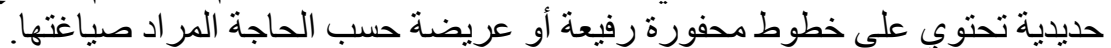

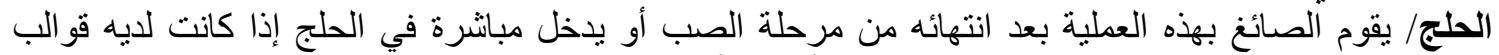

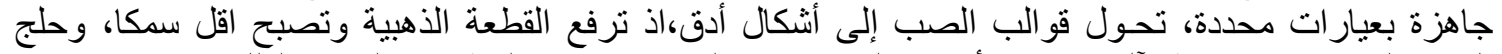

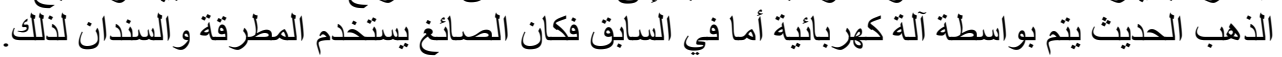

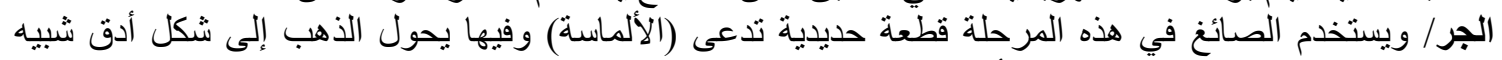

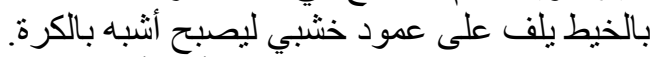

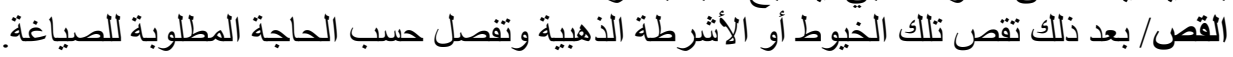

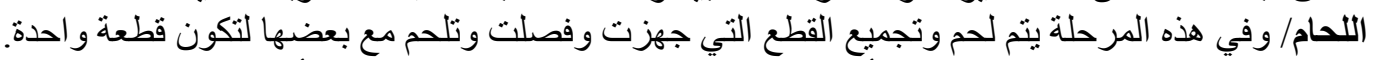
الجلي/ وهنا يتم إظهار لون الذهب الأصلي ويستخدم في ذلك مادة تشبه الملح إذ أن الذهب عند صهره يتغير لونه

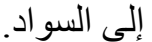

التهليش/ وفيها ينم تلميع الذهب و إعطائه اللمعان وتستخدم في ذلك ماكنة تسمى(الهلاشه).

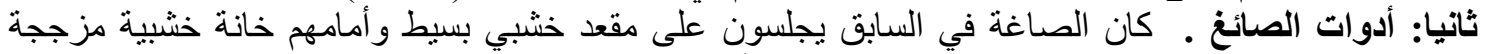

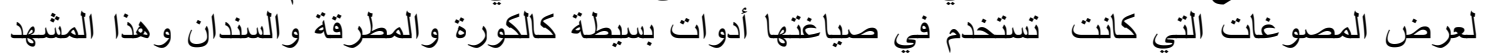

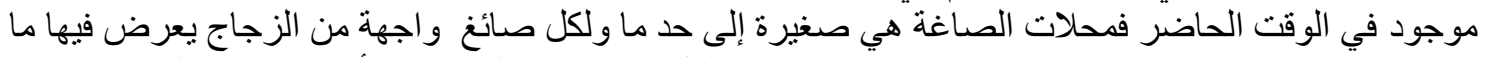

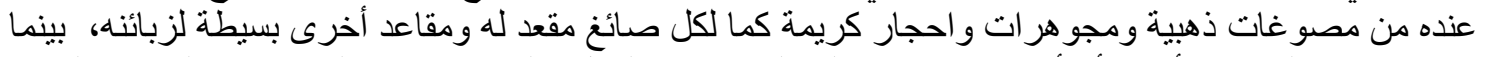

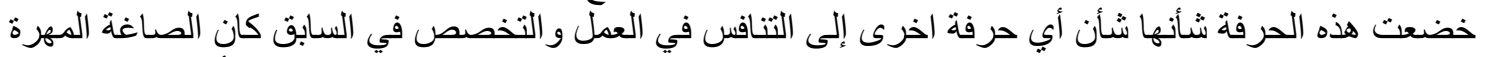

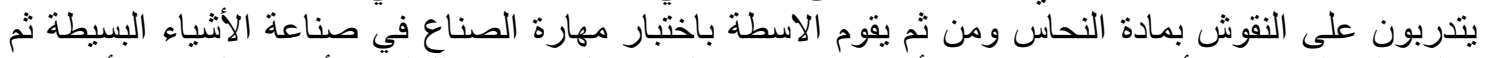

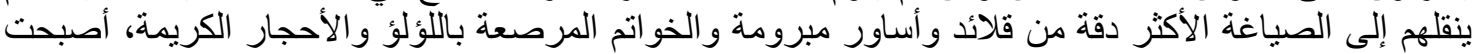

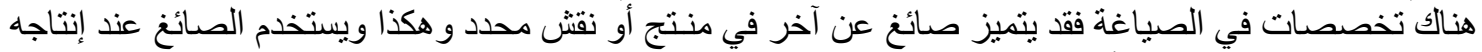
لقطعة ذهبية مجمو عة من الأدوات التي تطورت و اصبح بعضها كهربائيا ومنها ما يلي:( جريجس ، 13: 1982، 112- 


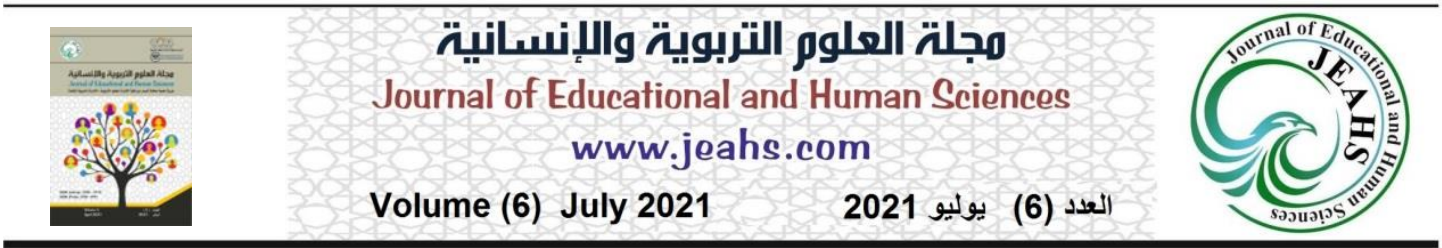

البوق: و هي مادة تشبه السكر تساعد على إذابة اللحام.

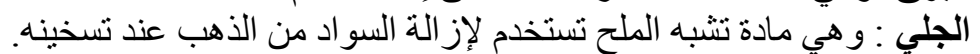

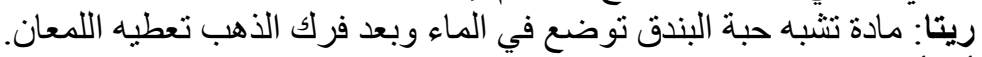

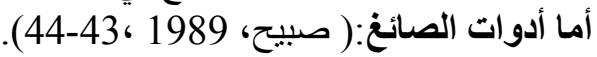
المته: عود من الخشب في اسفله ثقب حديدي وفي أعلاه خثبة أفقية يلف خبط من الأعلى يستخدم لنقب القطعة الذهبية.

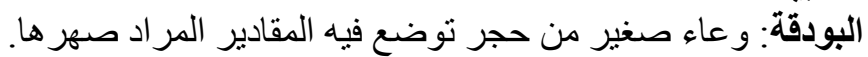
الغيزك: و عاء حديدي مستطيل الثكل يفصله فاطع فيله وسطي إلى قسمين يسكب فيه الذهب المصهور من اجل طرقه فيما بعد على أنثكال مختلفة.

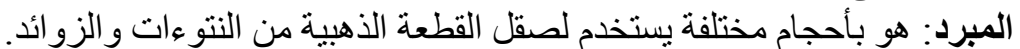
السندان/ حديده كبيرة ترتكز على ساق حديدية مدببة مثبتة في الأرض تنتعمل لطرق القطعة الذبة الذهبية بواسطة

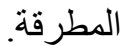
المقص: يستعمل لقطع وتقسيم الذهب و الفضة.

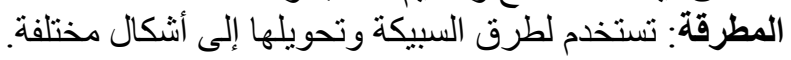

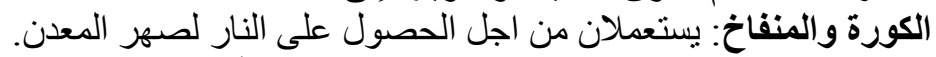

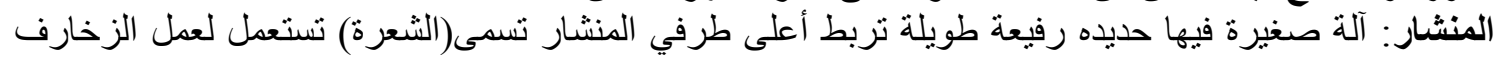

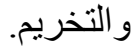

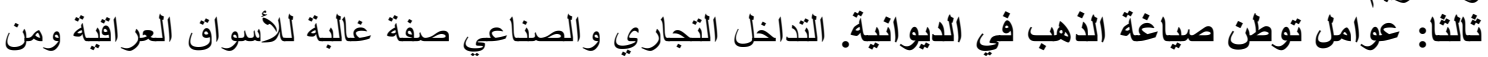

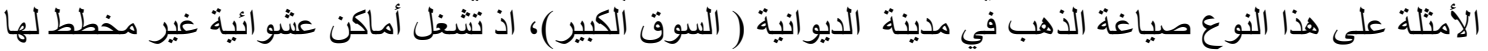

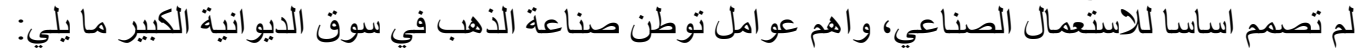

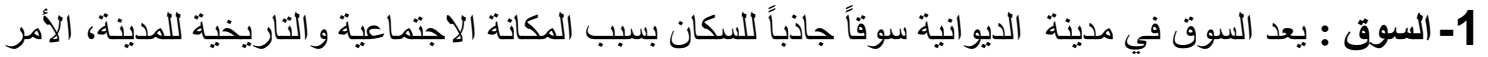

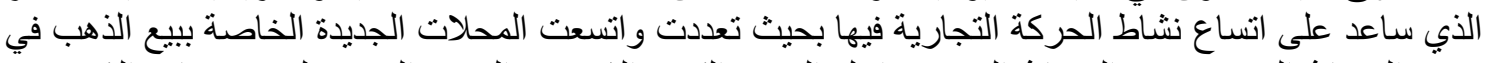
سوق الصياغ القديم وسوق الصياغ الحديث داخل السوق الكبير الذي يعد السوق الرئيس لبيع منتجات الذهب في الذهان في المدينة.

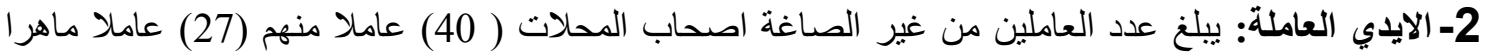

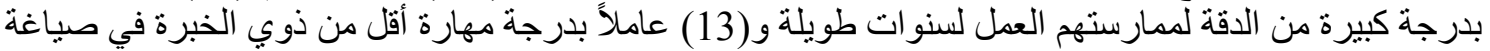

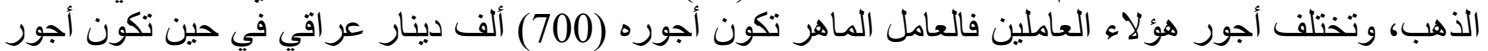

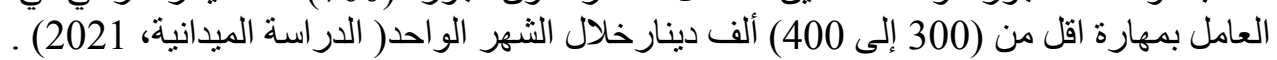

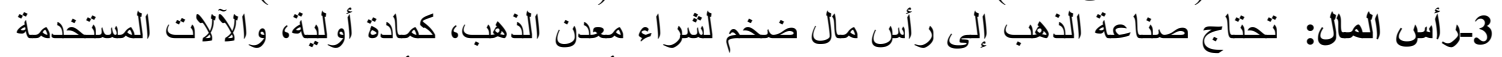

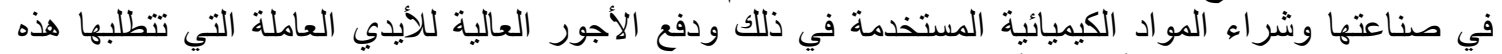

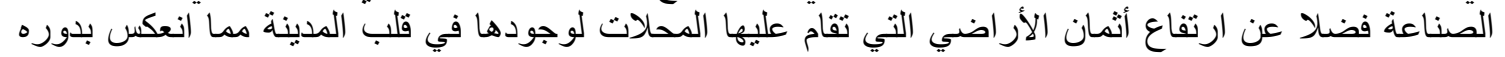
على ارتفاع ايجار ها بالمقابل. 4- المواد الأولية: يتم الحصول على المائ المواد الأولية للذهب إما عن طريق شرائها من أصحاب المحلات (محلات

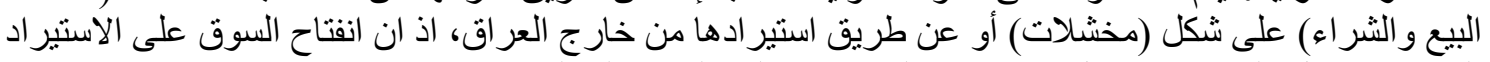

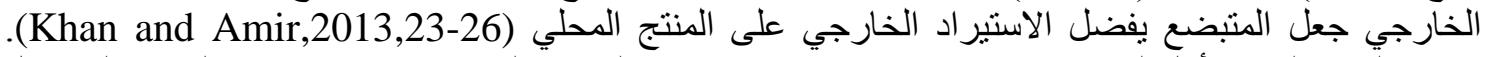

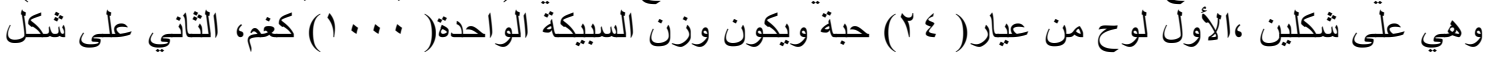

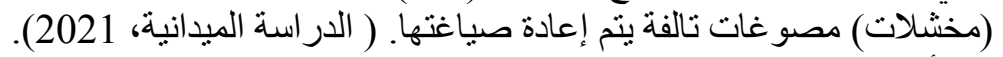

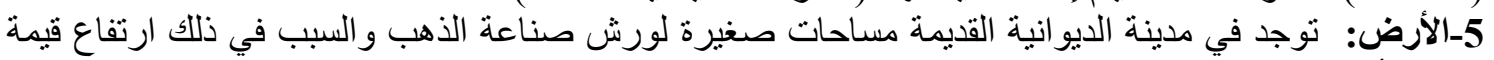

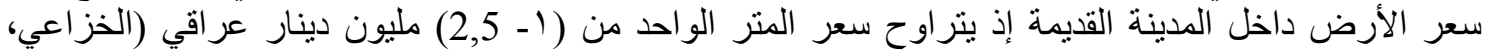

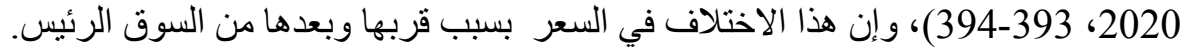

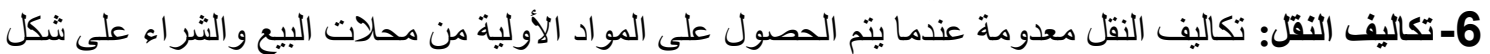

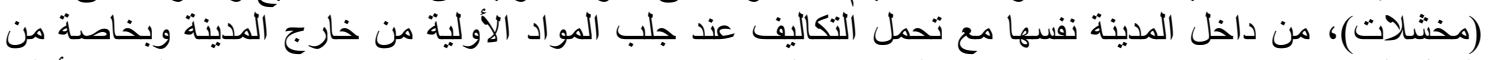

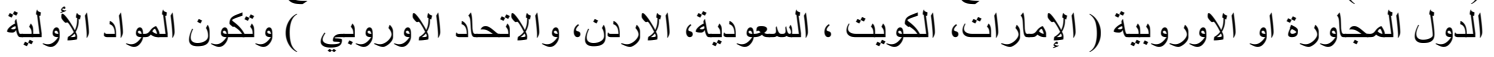




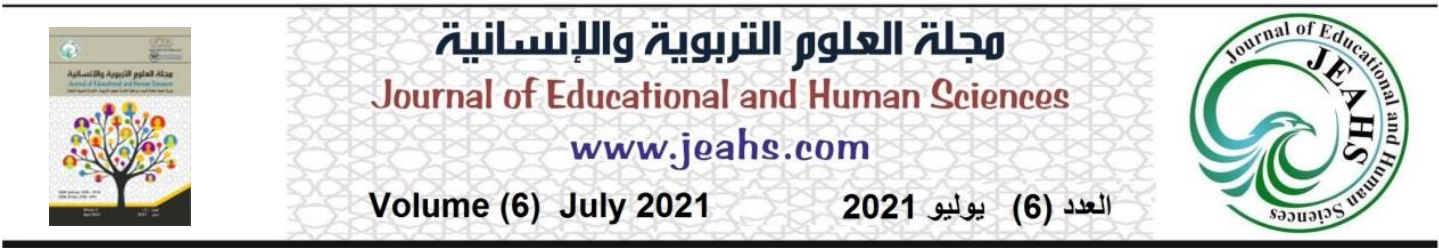

(الذهب) أكثر سعر ا من الذي يتم الحصول عليها من داخل المدينة بسبب تكاليف الثحن و النقل الخارجي.

الابحثث الرابع :صياغة الذهب في مدينة الديوانية.

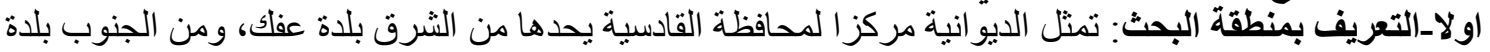

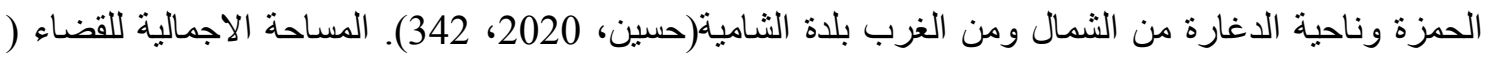

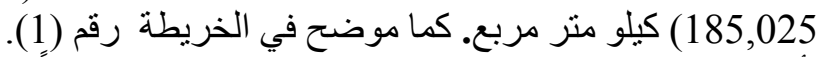

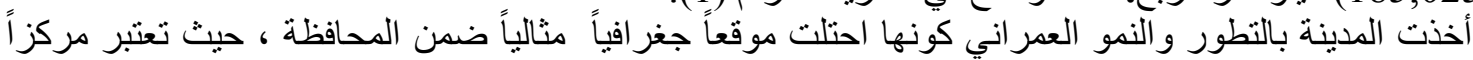

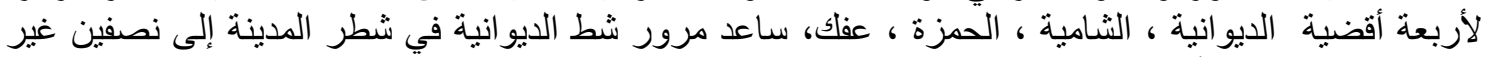

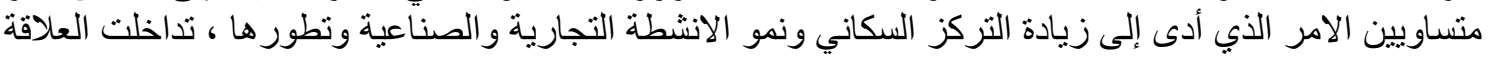

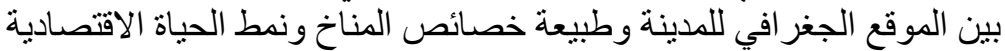
وسهولة النقل ونمو الانتطة الصناعية والتجارية وكثافة الطرق البرية وتركز الدوائر الحكومية ( الدجيلي، 2017،

الخريطة رقم (1) موقع مدينة الايوانية بالنسبة للوحدات الادارية في محافظة القادسية.

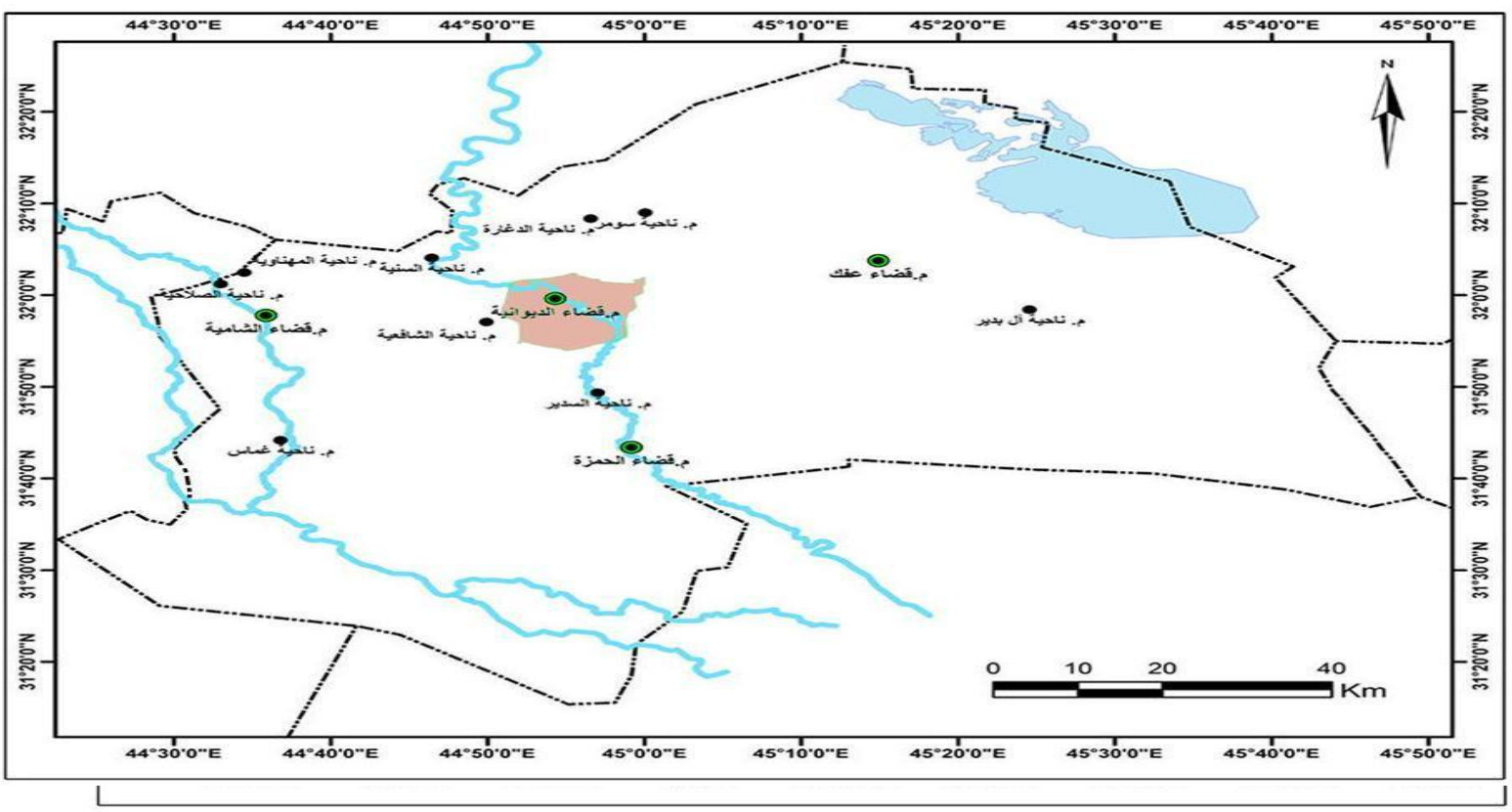

المصدر: جمهورية العراق، 2015 الهيأة العامة للمساحة، خريطة العراق الادارية،بغداد وزارة المورد المائية،

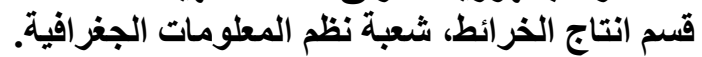
ثانيا: تأريخ الصياغة في المدينة.

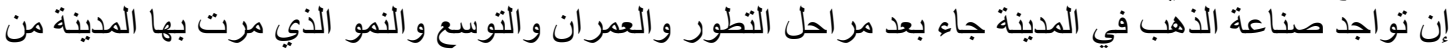

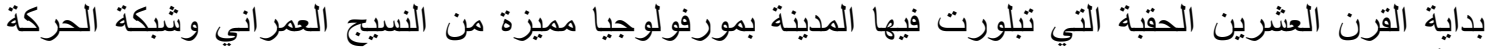

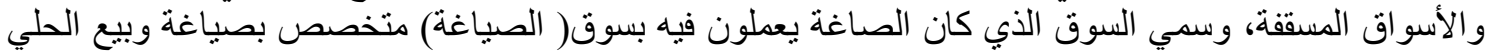

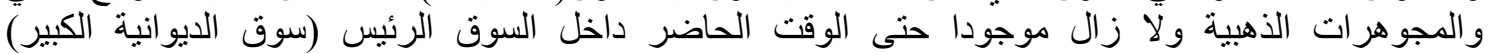

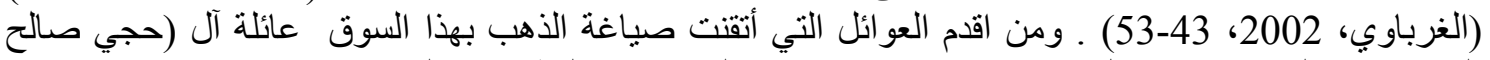

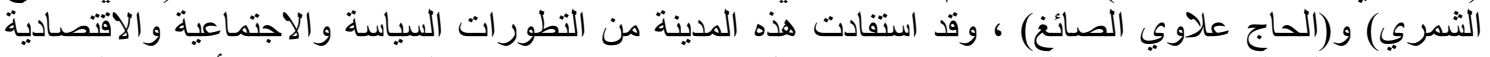

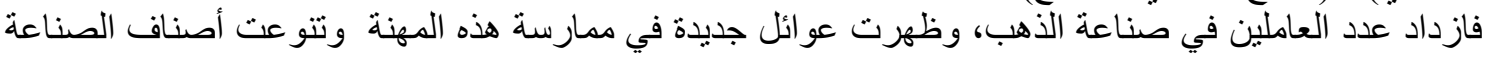

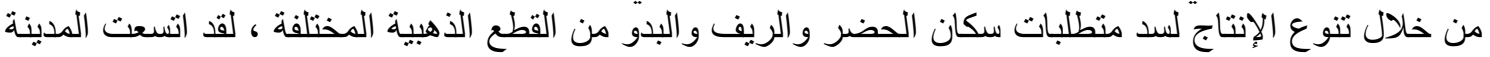

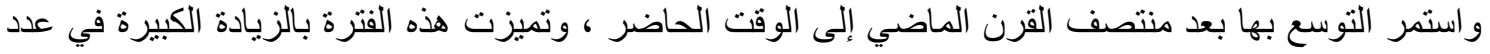




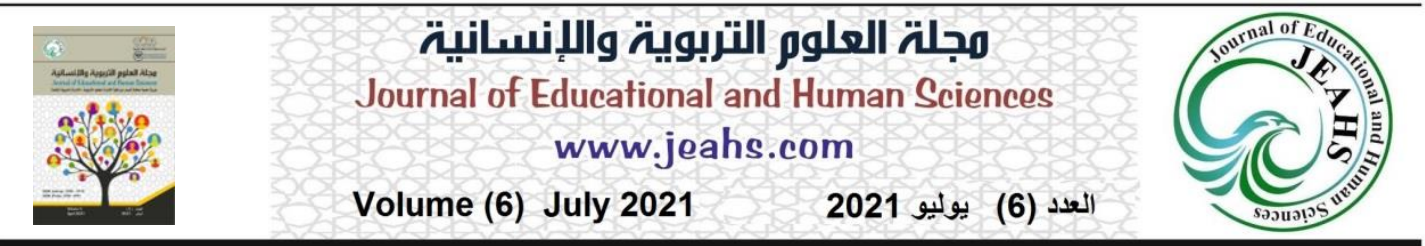

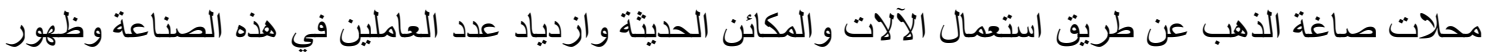

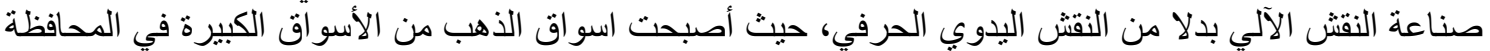

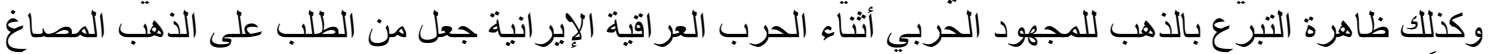

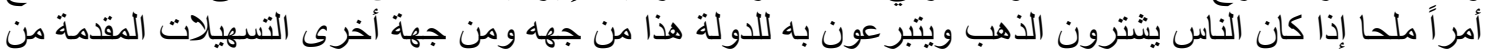

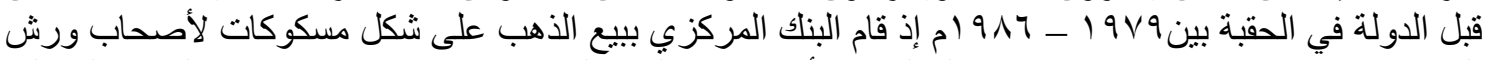

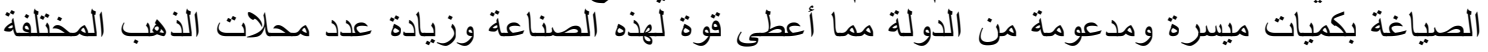

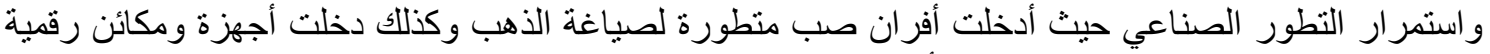

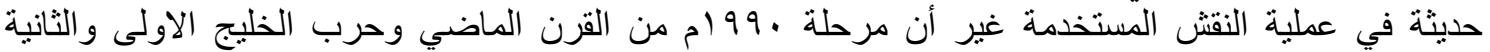

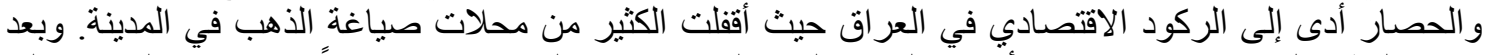

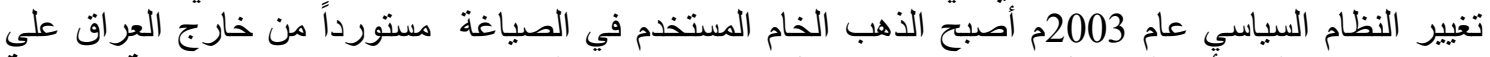

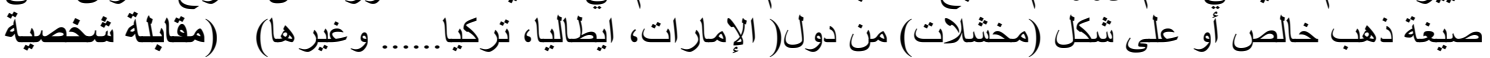

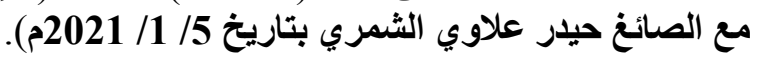

ثالثا: صياغة الذهب في المدينة.

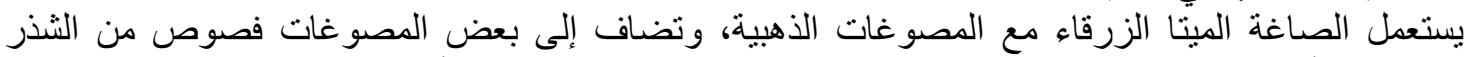

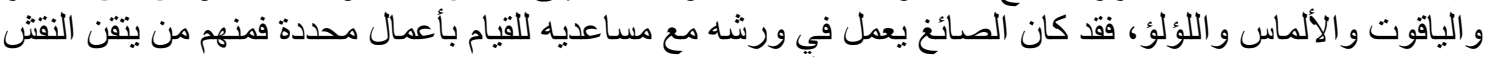

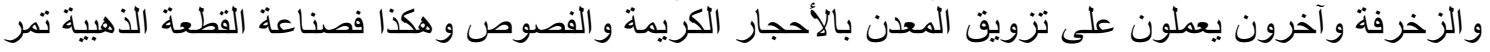

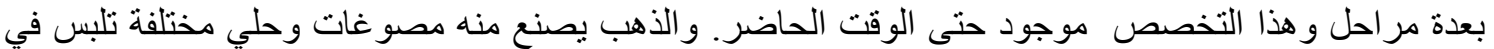

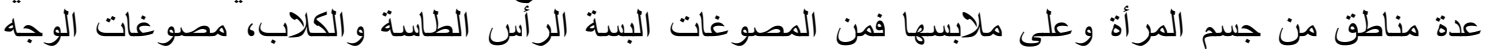

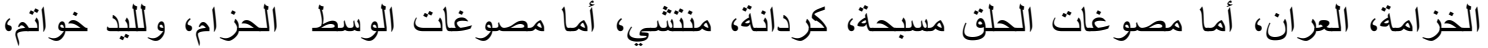

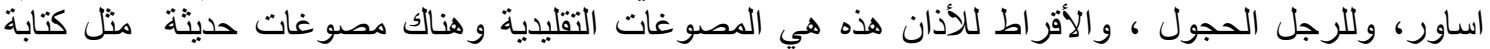

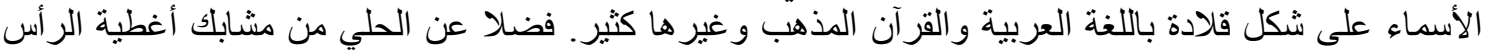

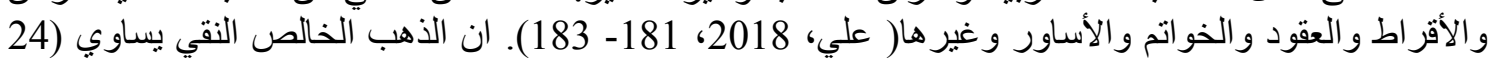

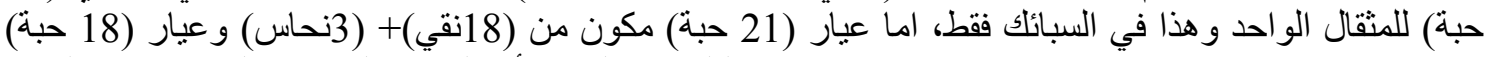

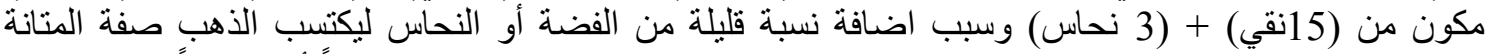

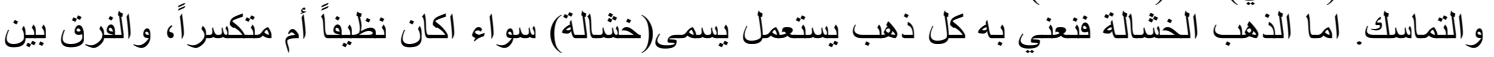

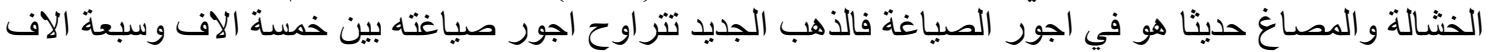

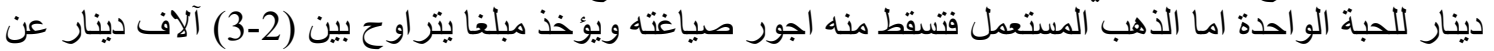

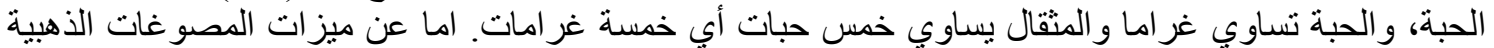

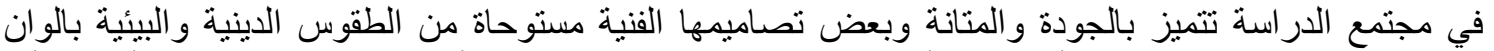

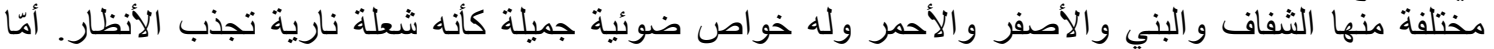

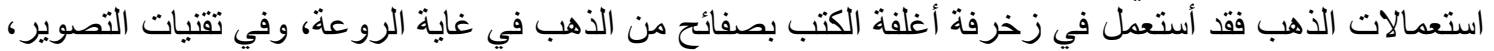

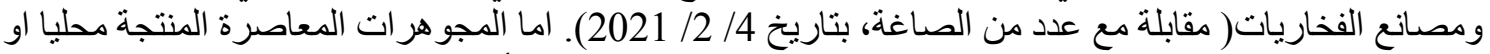

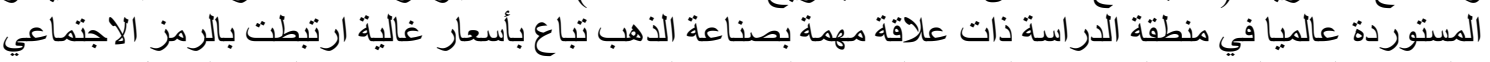

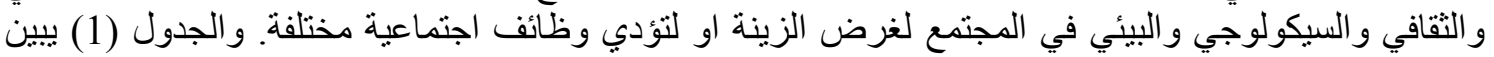

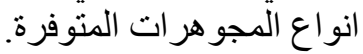




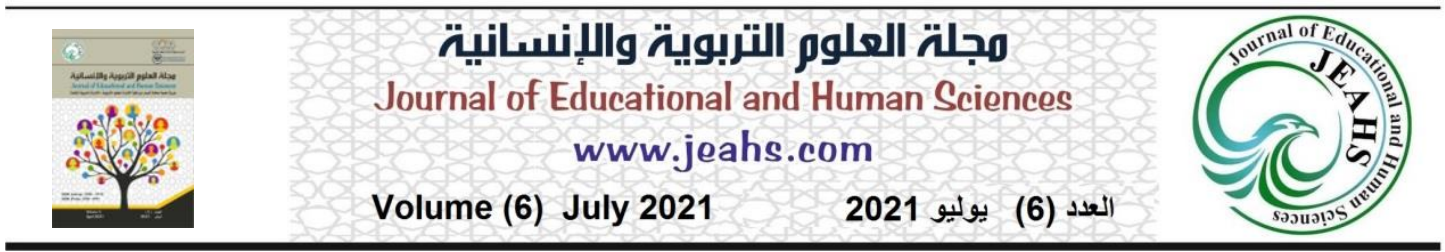

\section{الجدول (1) يبين انواع المجوهرات المتوفرة}

\begin{tabular}{|c|c|c|c|}
\hline انواع المجوهرات & المعدن & الصنف & $ت$ \\
\hline الاقراط، الرقبة، الصدر( القلائد) & ذهب_ذهب برازيلي & مجوهرات الرأس & 1 \\
\hline الخواتم، الاسـاور، الخلاخل، الحجل. & ذهب- فضة & مجوهرات الاطراف & 2 \\
\hline الابابيس، الماشات، الاحزمة & فضة_ ذهب & مجوهرات الملابس & 3 \\
\hline
\end{tabular}

الجدول من اعداد الباحث.

النماذج الاكثر رغبة وتداو لا بين النساء و المتمثلة ( الاقر اط، قلائد الرقبة، الخواتم، الاساور، الحجة الحجل) التي تثتاسب

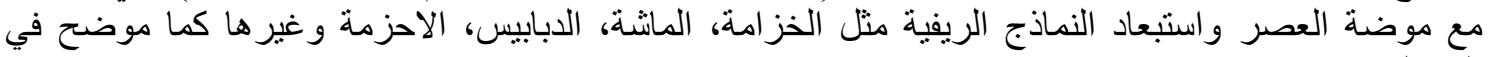

\begin{tabular}{|c|c|c|c|}
\hline \multicolumn{4}{|c|}{ الجدول (2) يوضح النماذج المتداولة في منطقة البحث. } \\
\hline المنشأ & نوع المعدن & النموذج & \\
\hline تركي & (ذهب )مطعم بشذر & اقراط & 1 \\
\hline عراقية & ذهب & قلادة الرقبة & 2 \\
\hline 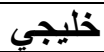 & (ذهب) مطعم بالبلاتين & الخاتم & 3 \\
\hline خليجي & (ذهب) مطعم بالبلاتين & اساور - - اور & 4 \\
\hline عراقية & ذهب & الحجل & 5 \\
\hline ايطالي & فضة_ ذهب & المدالية & 6 \\
\hline
\end{tabular}

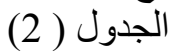

-

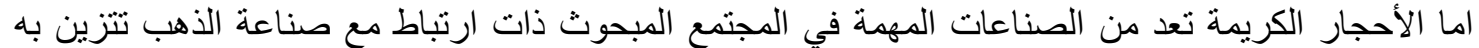

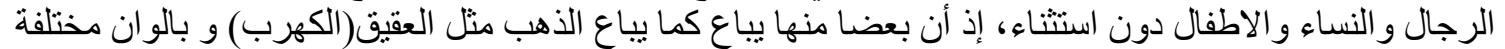

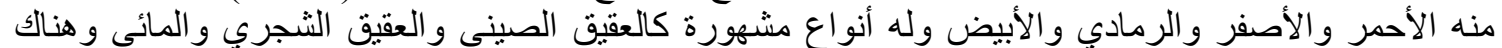

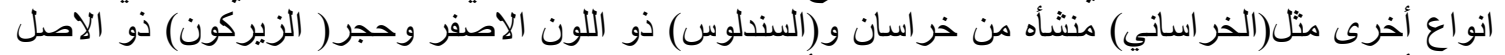

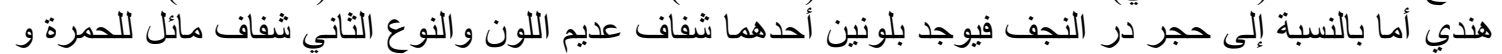

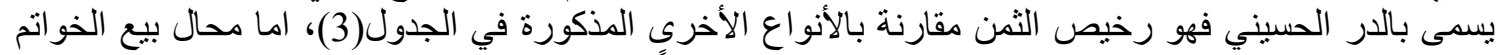

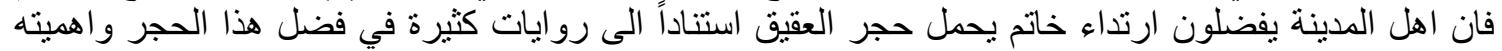

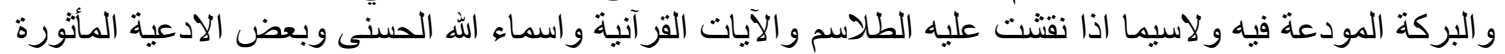

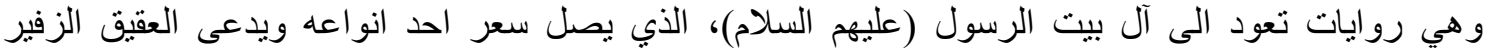

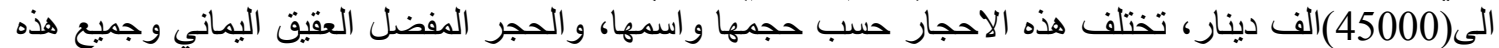

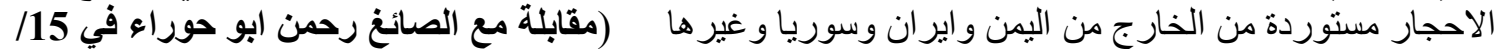

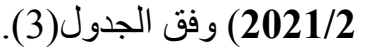

الجدول (3) يوضح نوع الاحجار الكريمة واسعارها في مدينة الديوانية.

\begin{tabular}{|c|c|c|}
\hline 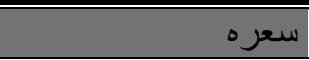 & نوع الاحجار الكريمة & ت \\
\hline $250.000-150.000$ & العقيق اليماني القيم & 1 \\
\hline 30.000 & العقيق اليماني الجديد & 2 \\
\hline 15.000 & العقيق شرف الثمس & 3 \\
\hline $25.000-10.000$ & العقيق السليماني & 4 \\
\hline $25000-5000$ & العقيق الخرساني & 5 \\
\hline $30.000-15000$ & الحديد الصيني & 6 \\
\hline 60.000 & الياقوت الاحمر & 7 \\
\hline 55.000 & المرجان الاحمر & 8 \\
\hline
\end{tabular}




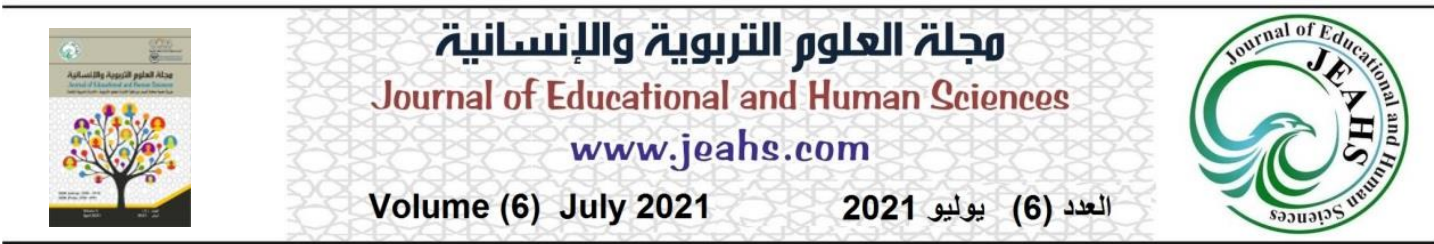

\begin{tabular}{|r|r|r|}
\hline 50.000 & 9 \\
\hline 50.000 & الزمرد الاخضر & 10 \\
\hline 65.000 & 11 \\
\hline
\end{tabular}

الجدول من اعداد الباحث بالاعتماد على الدر اسة الميدانية، 2021م.

رابعا: الأبعاد الاجتماعية والثقافية للأهب.

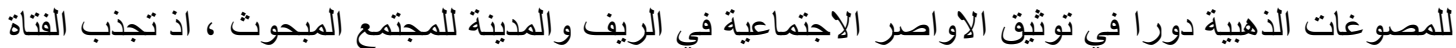

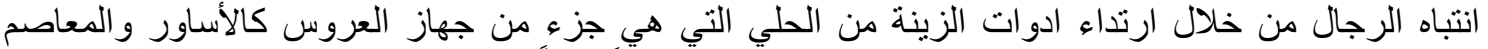

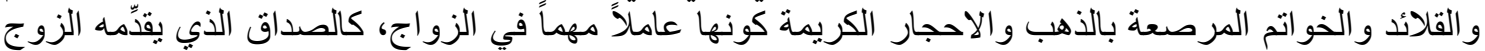

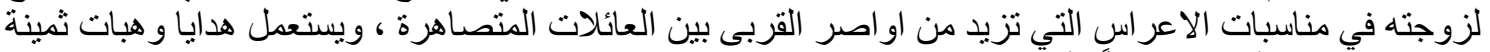

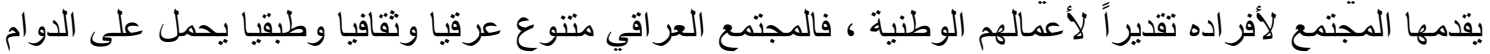

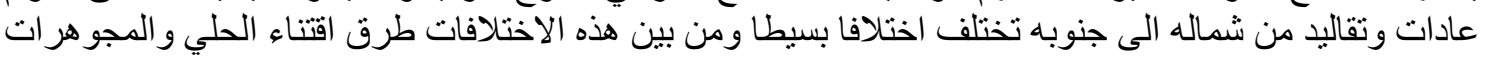

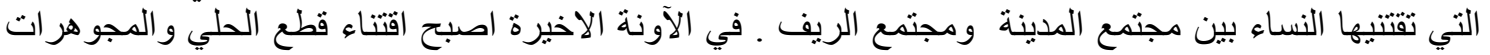

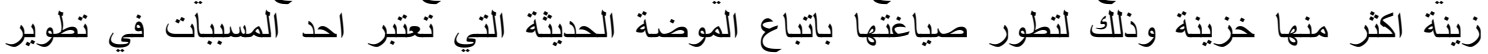

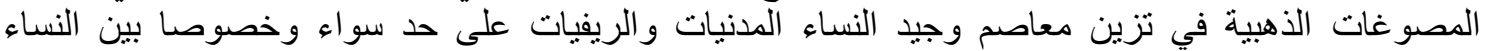

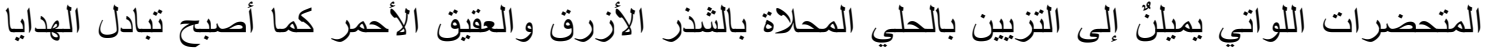

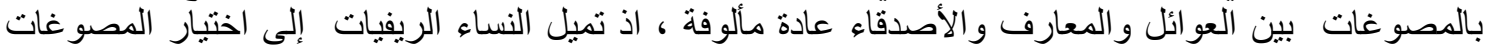

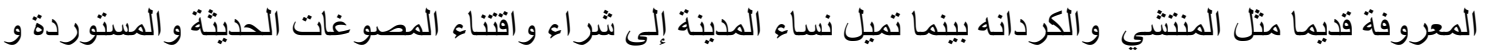

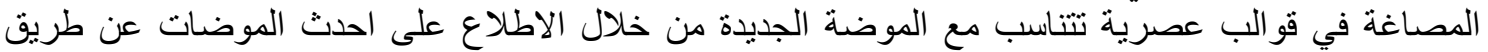

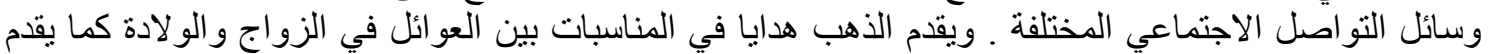

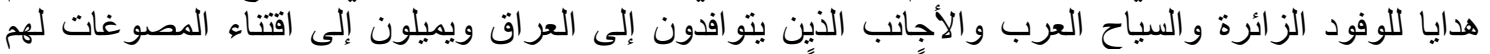

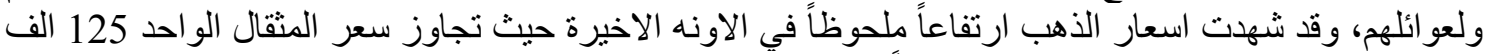

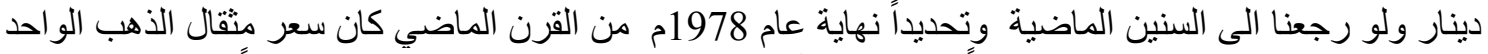

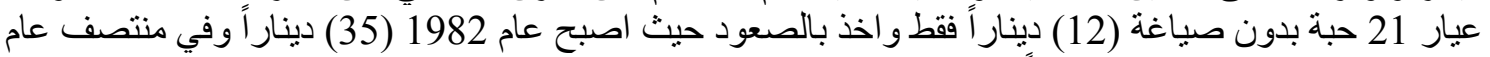

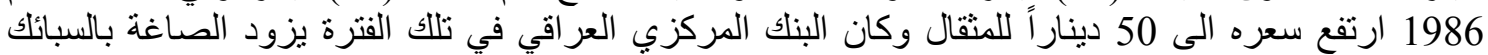

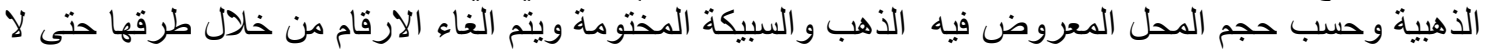

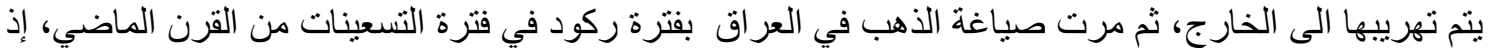

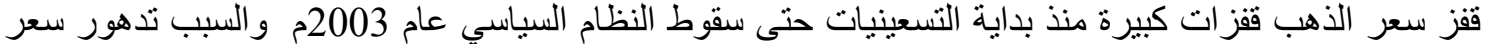

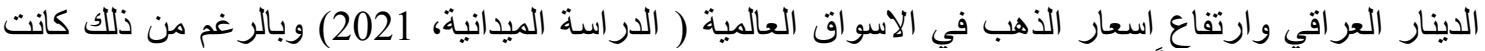

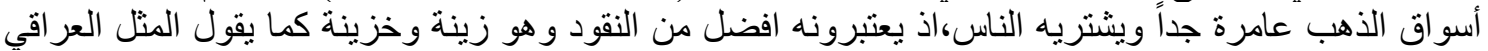

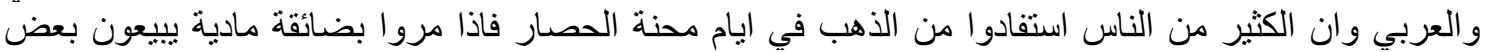

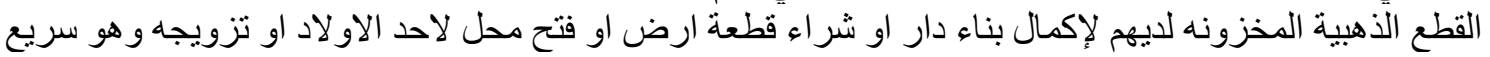

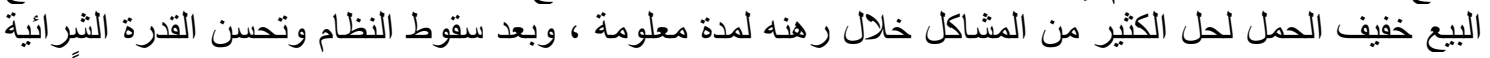

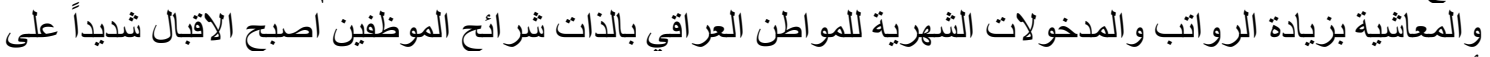

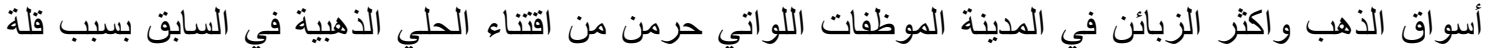

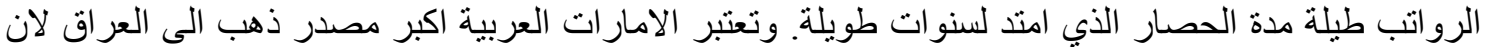

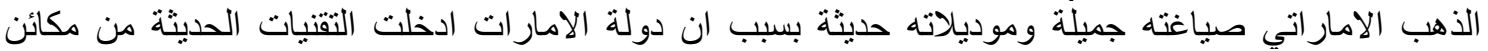

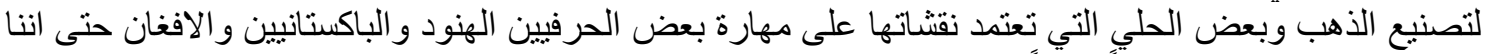

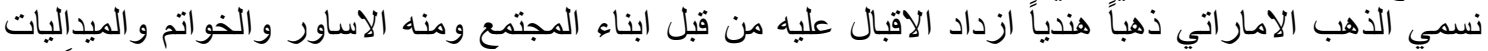

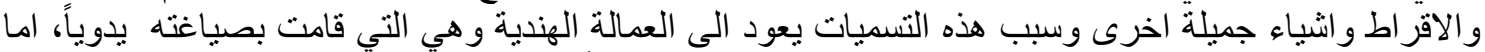

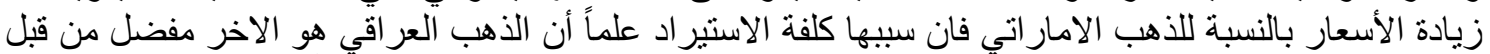

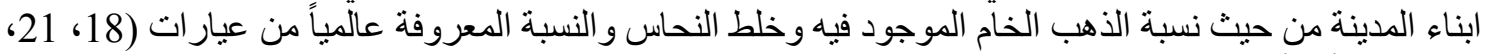

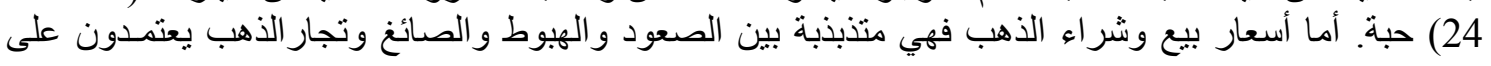




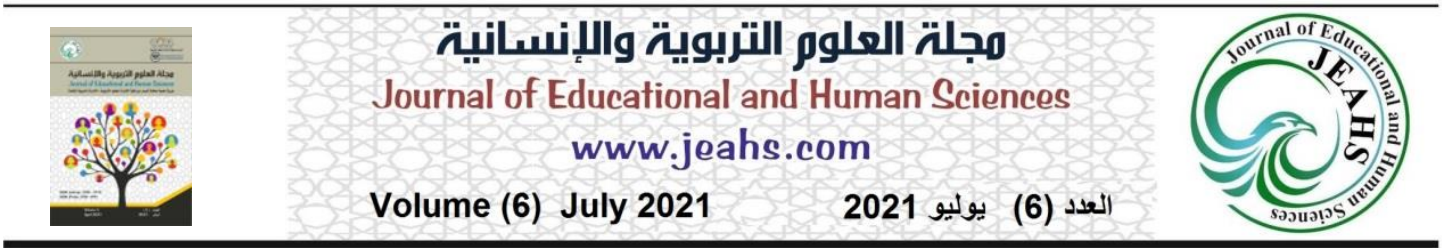

وسائل التو اصل الاجتماعي لمعرفة سعر الذهب.( الدراسة الميدانية، 2021م).

\section{خامسا: السياسة الحكومية المستقبلية لصياغة الأهب في مدينة الايوانية:}

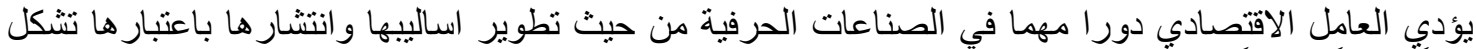

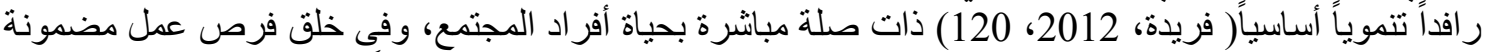

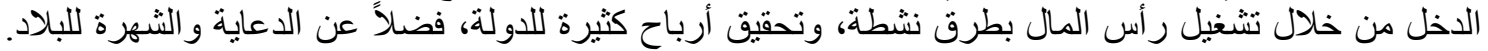

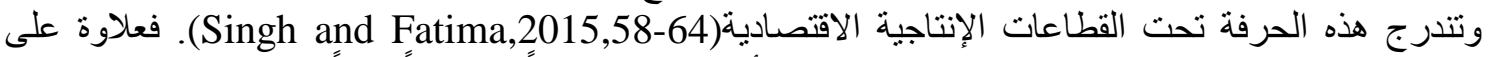

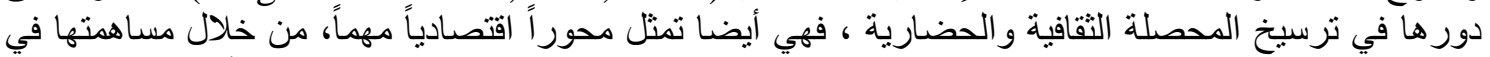

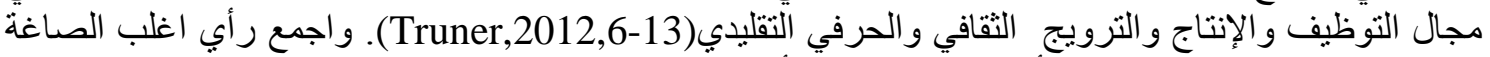

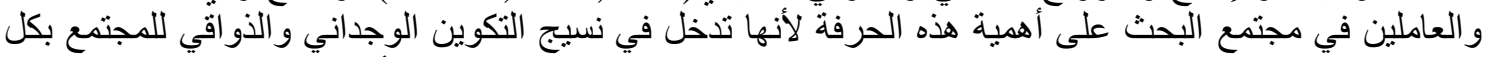

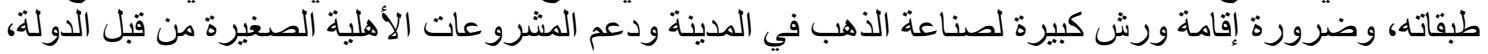

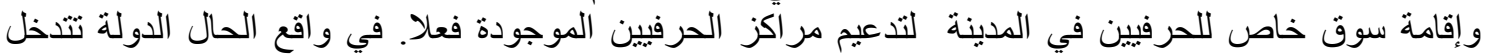

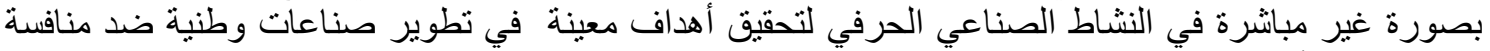

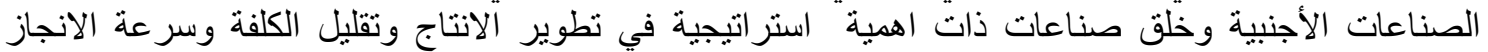

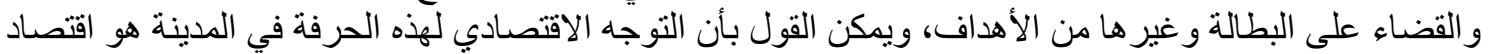

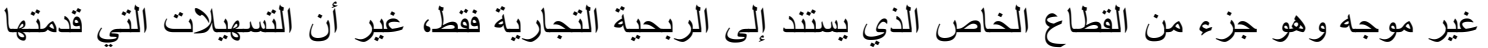

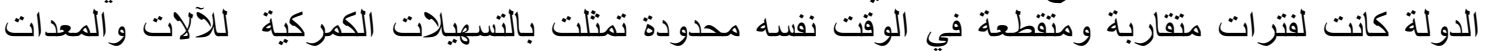

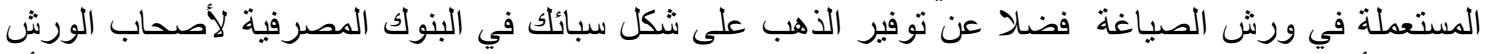

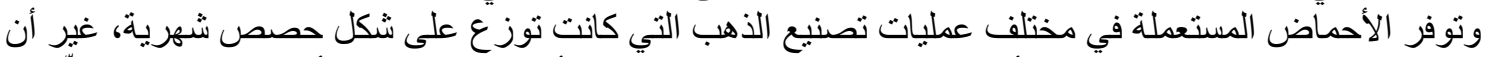

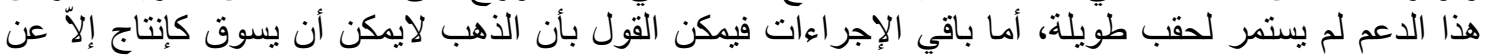

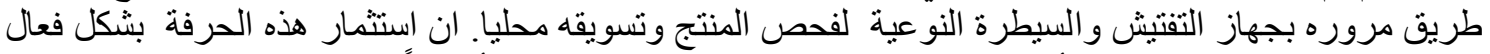

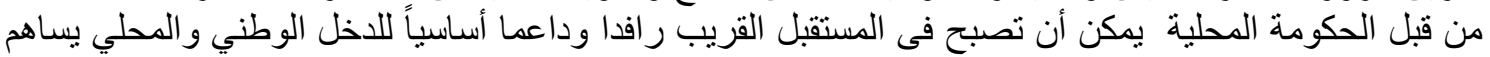
في التنمية الثاملة للمجتمع المحلي.

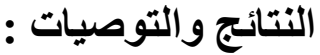

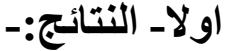

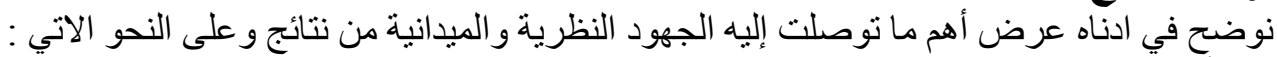

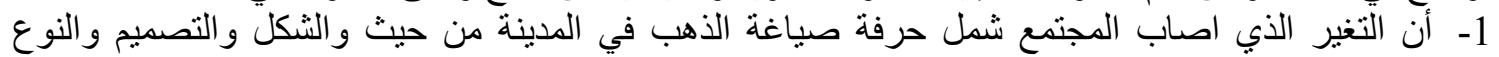
و البيع. 2- دخول المكننة الحديثة و الكهرباء والقوالب الجاهزة كأدوات يعتمد عليها الصائغ في عمله بعد أن كان عمله 3- "طهور عدد من الصاغة مهمنهم عرض الذهب وبيعه من دون معرفتهم بأصول الصياغة أي أنهم بمثابة تجار لللذهب و هذا ما لم يكن موجود سابقا. 4- التغير ات السلبية التي طر أت على الذهب العر اقي فقدان مصداقيته ودقة معياريته و التناعب فيه بسبب عدم فحصه من قبل جهاز السيطرة النوعية.

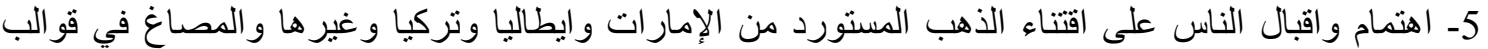

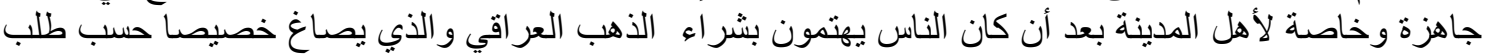
المشتري. 6- انتشار محلات الصاغة في الآونة الأخيرة في مناطق مختلفة من سوق الديو انية الكبير بعد أن كانت محصورة في سوق واحد هو سوق الصاغة التهار القديم.

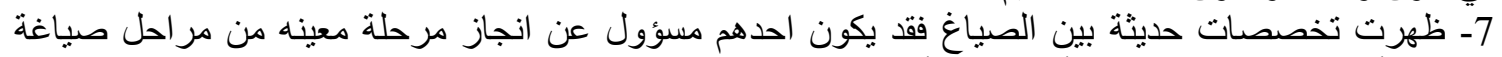
الذهب و أخر مسؤول عن مرحلة أخرى بعد أن كان العمل التقليدي القديم الصفة السائدة لدى الصائغ. 


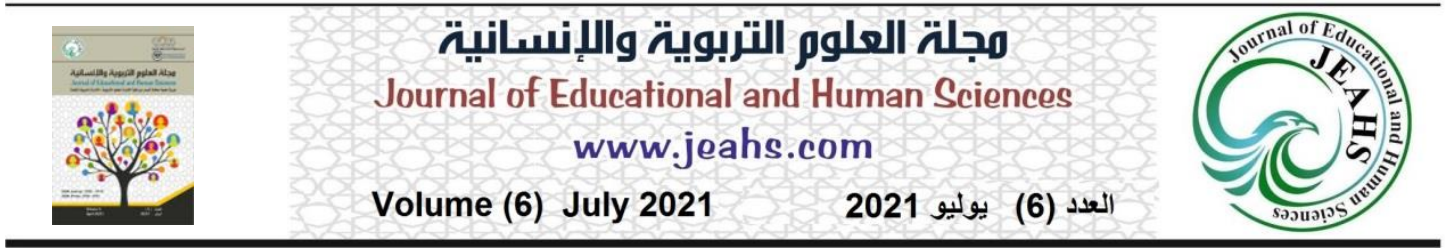

في اطار ما ورد من نتائج خلص البحث التو الى مجمو عة من التوصيات المناسبة المتمثلة بالاتي:ثاتيا_التوصيات:-

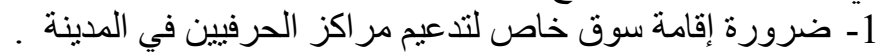

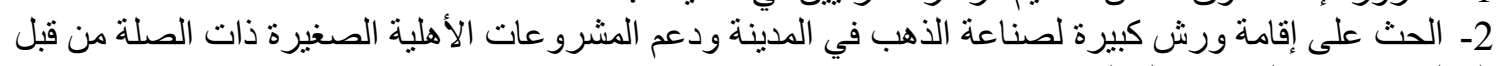

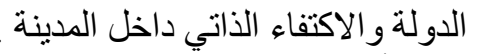

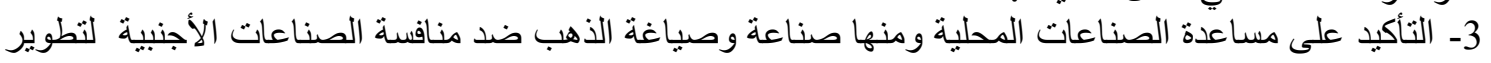
وخلق صناعات عر اقية ذات الهية استراعراتية التاعية. 4ـ الاهتمام بالذهب العر اقي لإرجاع مصدافية الهيته و الثقة به من خلال الاهتمام بنقاوته وتثبيت نسبة الثوائب فيه من قبل جهات حكومية رسمية مسؤولة.

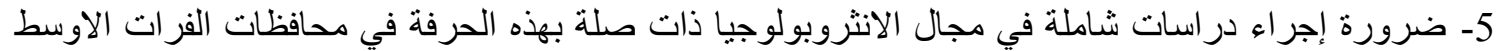

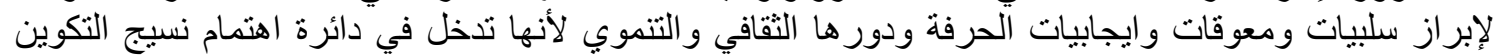
الوجداني و الذوقي للمجتمع بكل طبقاتها.

1- جمهورية العراق، الهيأة العامة للمساحة، 2015، خريطة العراق الادارية، بغداد، وزارة المورد المائية، قسم

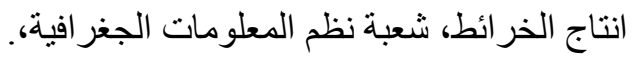

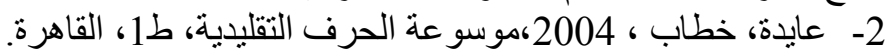

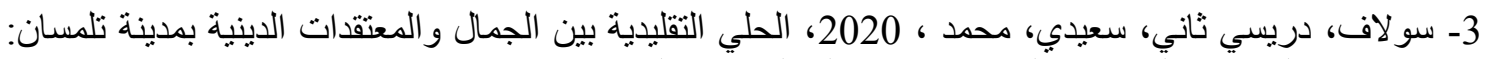

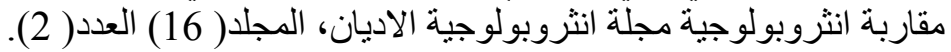
4- ناصر ، رامي.،2020، الحرف التقلئليدية اللبنانية و اشكالية التنمية المستدامة ،الجامعة الاسلامية، لبنان، مجلة انثروبولوجيا، المجلد( 6) العدي، العدب(20). 5- الغرباوي، رعدية، القعبد الحسين، 2002،العر اق،الوظيفة السكنية لمدينة الديوانية، رسالة ماجستير منشورة في جامعة القادسية. 6- دياب، سهيل رزق ،2003، 2003، مناهج البحث العلمي، غزة، فلسطين.

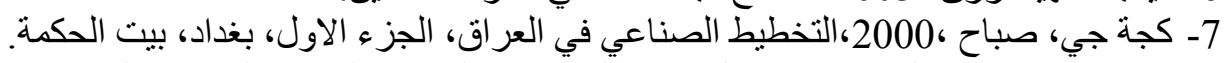
8- حسين، صبرية صبية علي، 2020، العراق، آلتداعيات الصحية لسكان الجية المناطق العشوائية بئة في مدينة الديوانية،

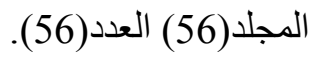

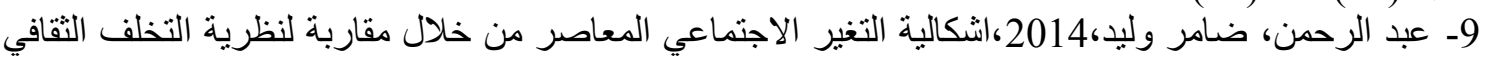

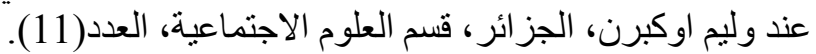

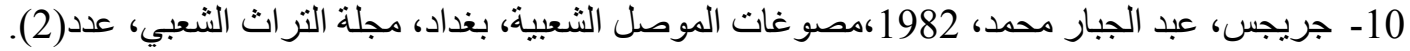
11- عبد الرحمن، عبد المجيد احمد، 2002، مستقبل الحرف والصنافئاعات التقليدية في السودان: منظور انثروبولوجي، مجلة در اسات حوض النئ النيل، العدد الرابع. 12- النعيمي، عبد الوهاب، 2006،سوق الذهب في الموصل، مجلة موصليات، عدد (15)، مركز دراسات الموصل. 1النيدي 13- المالكي، عبد علي سلمان،2007، الانثروبولوجيا الاجتماعية، ط1، العر اق، مطبعة النجف الاشرف. 


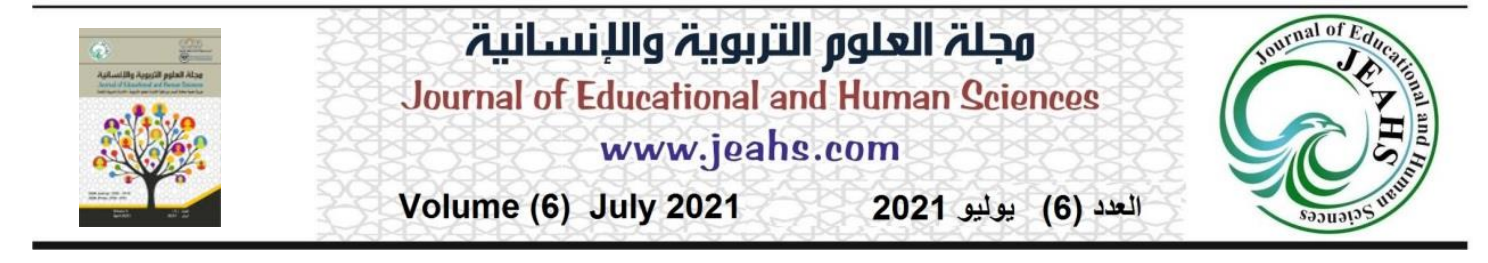

14- الخزاعي، عبير عدنان خلفة، 2020، التحليل المكاني لقيمة اسعار الاراضي في مدينة الديوانية، العراق،

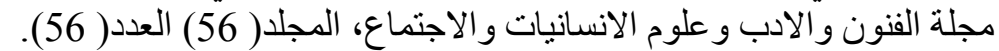

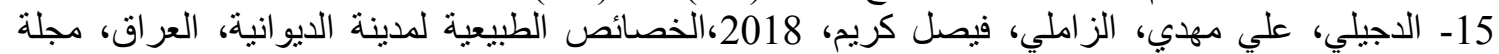

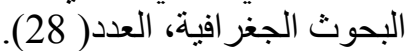
16- غانم، عماد، 2009، 2012، كان بامكان، الموصل، مكن، مكتب تبارك.

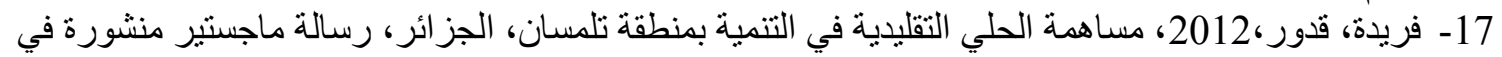

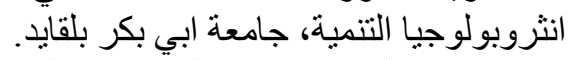

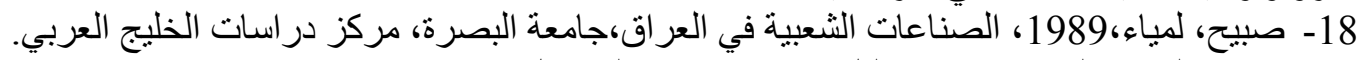

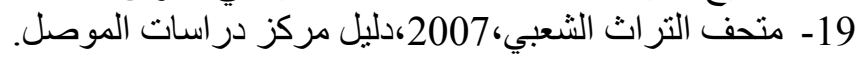

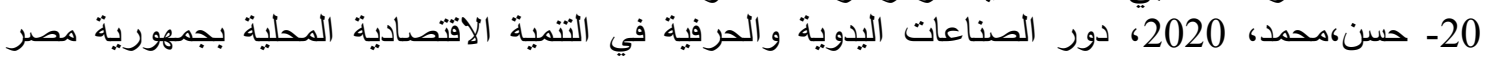

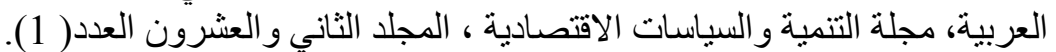

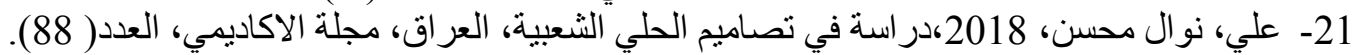
22- الجادري، وليد ،1982،العر اق، الحرف والصناعات اليداتية في العصر الاشوري المتأخر، مطبعة الحرية. 23- Godelier, M. (2015).The field and the tools of the anthropologist, in Anthropology for all: Proceedings of the Aubervillies conference.

24- Khan,W\& Amir, Z. 2013. study of Handicraft Marketing Strategies of Artisans in uttar Pradesh and its Implications. Research Journal of Mangement Sciences, Vol.(2)(2). 25- Kokko, S \& Patrick Dillon, Crafts and craft education as expressions of cultural heritage: individual experiences and collective values among an international group of women university students, Springer Science+Business Media B.V.

26- Lauretto. M, Nakano. F, Pereira. C\& Stern, J. 2012, Intentional Sampling by Goal Optimization with Decoupling by Stochastic Perturbation University of Sao Paulo Conf-Brazil.

27- Leat, D. 2005. theories of social change, London, sage publications.

28- Parisi, D, Cecconi, F\& Natale, F. 2010. Cultural change in spatial Environments: The role of cultures, The journal of conflict Resolution,vol.(47),no.2.

29- Samuel B. 1991. Geochemistry of gold in hydrothermal deposits, Second printing, United States.

30- Singh, A. K\& Fatima, S. 2015. Role of Handicraft sector in the Economic Development of uttar Pradesh. International Journal of Researchgranthaalayah,Vol.(3)(1).

31- Truner, M.(2012). world Heritage and Sustainable development: world Heritage Review, Vol (65).

32- Varnum1, M\& Grossmann, L. 2017, Cultural Change: The How and the Why, Arizona State University and 2University of Waterloo, Perspectives on Psychological Science. 


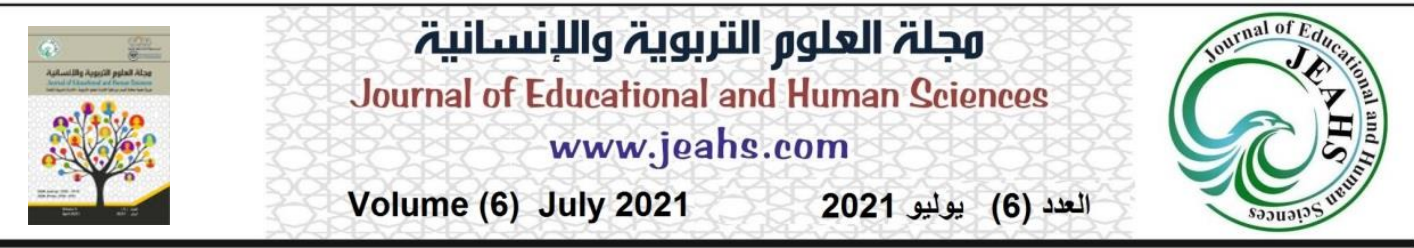

33- Wahab, S\& Rose, R. 2012. Defining the Concepts of Technology and Technology Transfer: A Literature Analysis, National Defence University of Malaysia, Kuala Lumpur 57000, Malaysia, Published by Canadian Center of Science and Education, Vol. 5, No. 1;

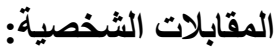

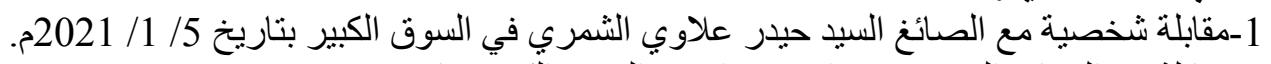

$$
\begin{aligned}
& \text { 3-مقابلة مع الصائغ السيد رحمن ابو حور اء في السوق الكباء الكبير بتاريخ 15/ 2021/ 2021م. } \\
& \text { 2-مقابلة مع عدد من الصاغة في السوق الكبير بتاريخ 4/ 2/ 2021م. }
\end{aligned}
$$




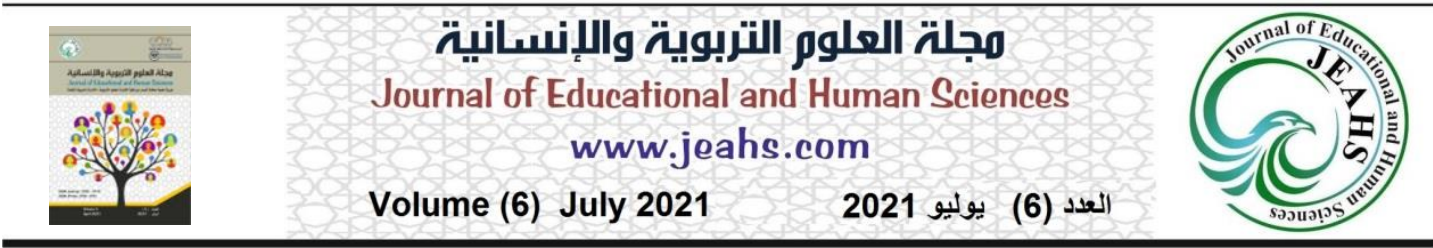

ملحق رقم ( 1) يوضح نماذج الحلي الذهبية الموجودة في منطقة البحث.

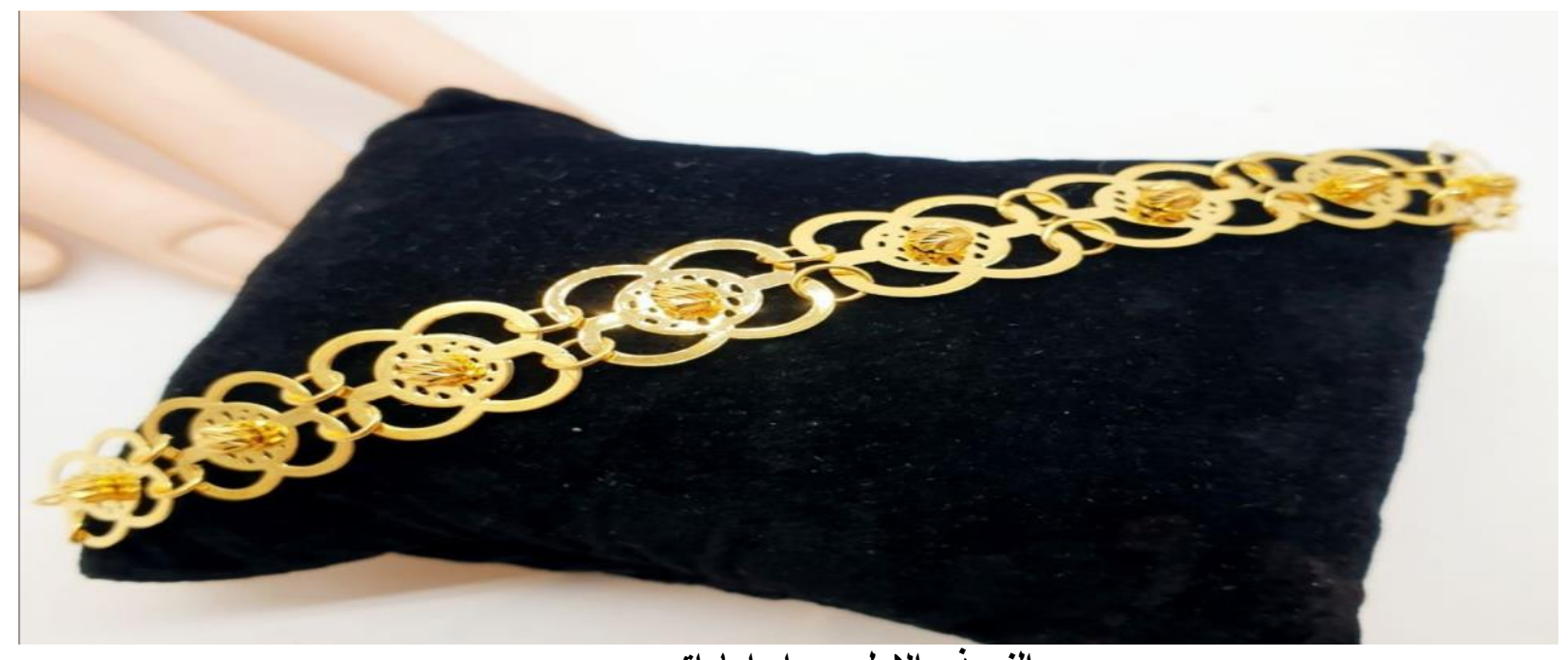

النموذج الاول: سوار اماراتي

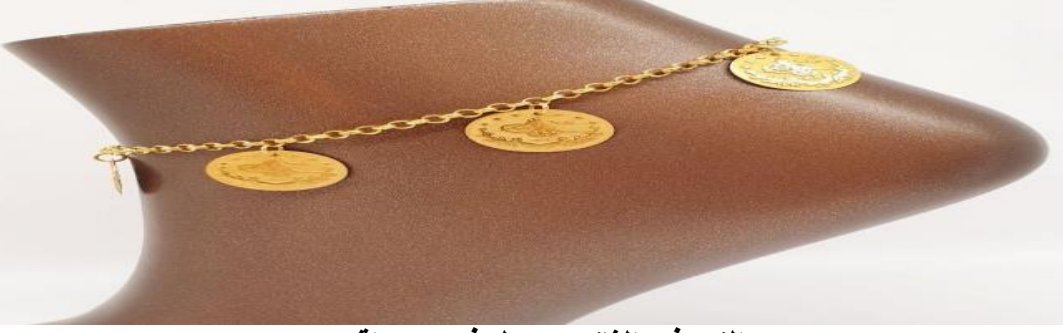

النموذج الثاني: حجل ذهب عراقي 

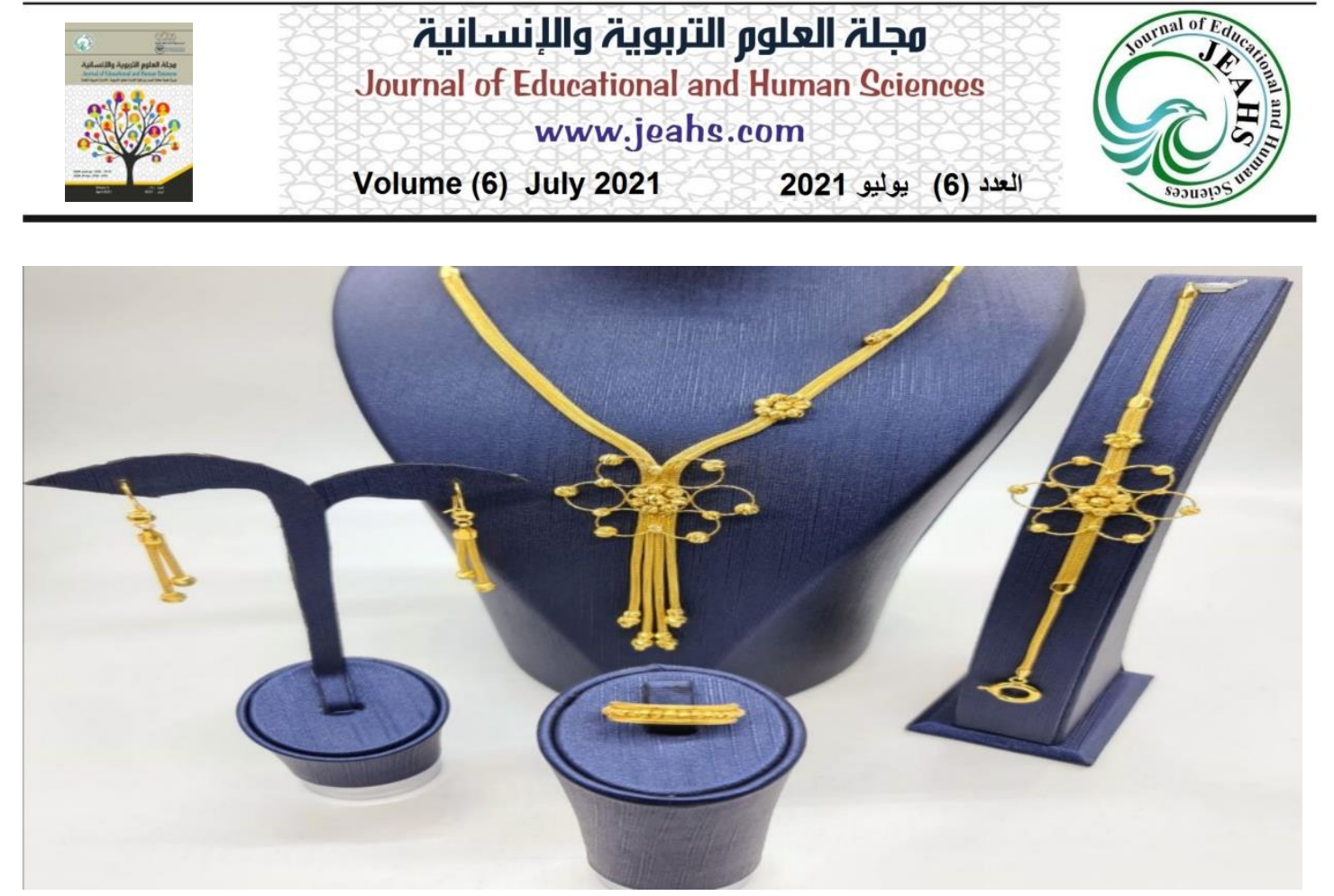

النموذج الثالث: قلادة ايطالية

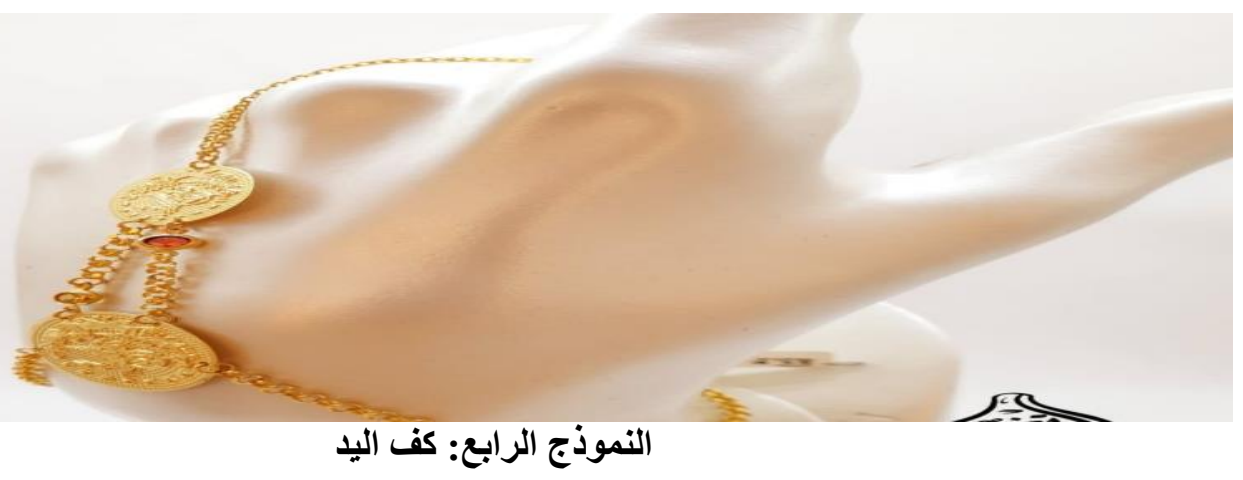




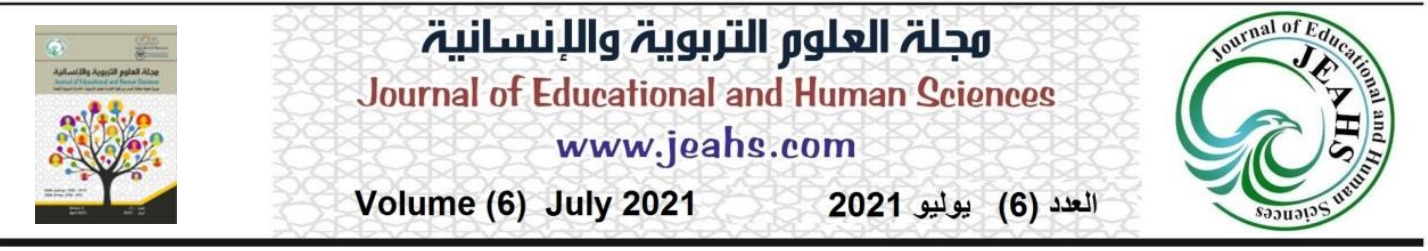
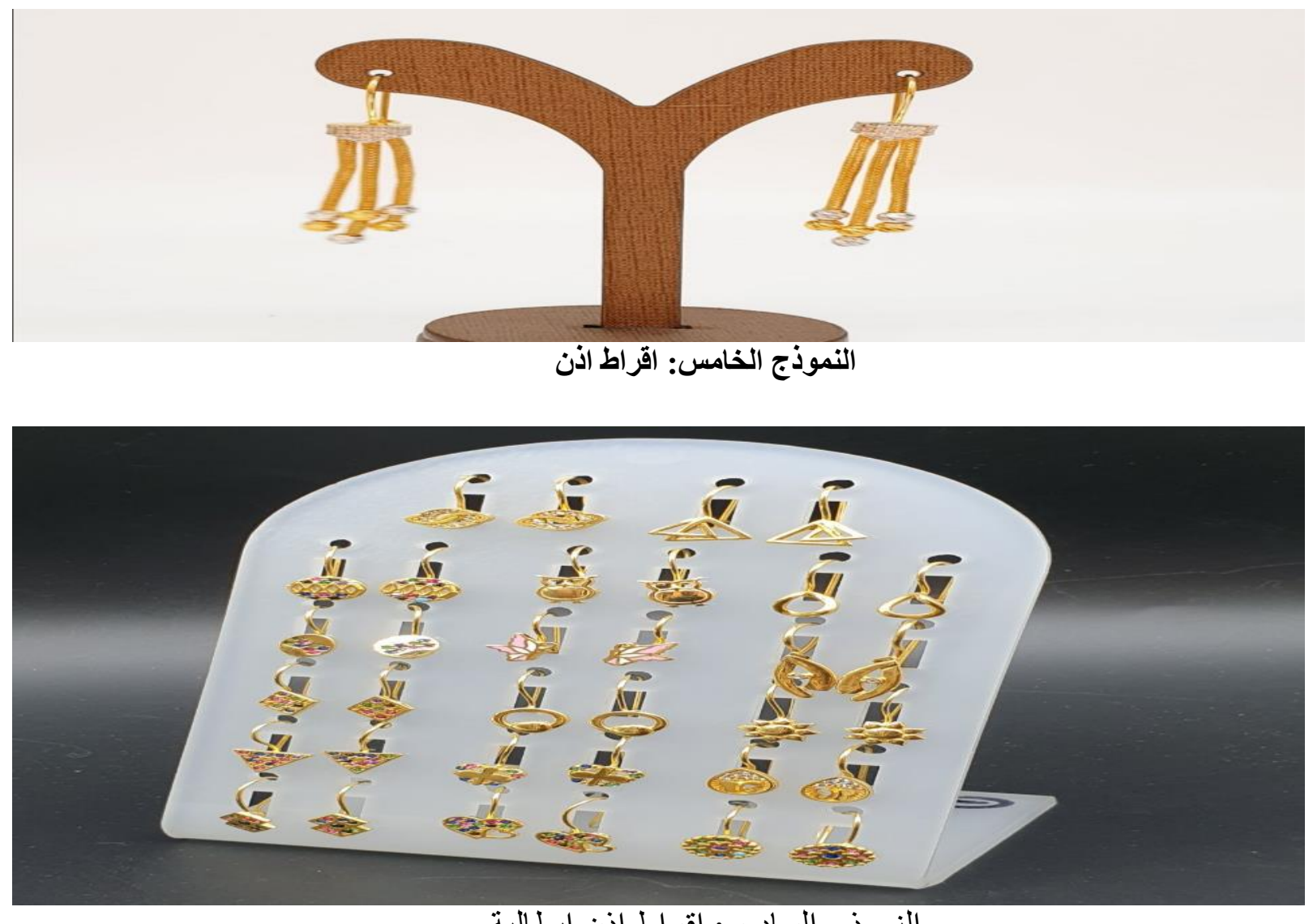

النموذج السادس: اقر اط اذن ايطالية 